Série des Documents de Travail

$n^{\circ}$ 2012-08

\title{
The Contribution of Housing to the Dynamics of Inequalities
}

\author{
M. SIDIBÉ ${ }^{1}$
}

March 27, 2012

Les documents de travail ne reflètent pas la position du CREST et n'engagent que leurs auteurs. Working papers do not reflect the position of CREST but only the views of the authors.

1 CREST, 92240 Malakoff and CNRS, GATE Lyon-St-Etienne, UMR 5824, France. modibo.sidibe@ensae.fr 


\title{
The Contribution of Housing to the Dynamics of Inequalities
}

\author{
Modibo Sidibé *
}

March 27, 2012

\begin{abstract}
This paper proposes a unified framework for the analysis of inequalities. In contrast to the former literature on inequalities, housing is included as a major determinant of individual saving behavior. Disparities across locations affect individual outcomes in both labor and education markets. In a Bewley-Huggett-Aiyagari type model where several frictions are represented, the model allows for segmentation between homeowners and renters in the housing market, imperfection in the capital market and residential mobility over the life-cycle. Moreover, individual location is assumed to affect labor productivity, wealth accumulation via the dynamics of housing prices and the human capital acquisition process of the next generation. The dynamics of prices combined to bequest motive provide the perfect framework to understand the tenure choice of individuals. Furthermore, the fixity of housing supply in each neighborhood combined with borrowing constraints prevent some households from living in their preferred area, which leads to segregation. Using this general framework, the paper contributes to the understanding of the complex relationships between labor, housing and education markets. Finally, several experiments aimed at decreasing the level of inequalities at the individual and location level are provided.
\end{abstract}

Keywords: Heterogeneous Agents, Inequalities, Wealth distribution, Housing

JEL Classification: E24 I30 R23

${ }^{*}$ CREST, 92240 Malakoff and CNRS, GATE Lyon-St Etienne, UMR 5824, France, modibo.sidibe@ensae.fr. I am extremely grateful to Florence Goffette-Nagot for her guidance. I thank Christian Belzil, Chris Ferrall, Susumu Imai, Francis Kramarz, Huw Lloyd-Ellis, and Etienne Wasmer for helpful comments. 


\section{Introduction}

A new empirical literature has emerged that examines the determinants of inequalities over lifetime. Huggett et al. (2011), Keane and Roemer (2009), de Nardi (2004) and Heer (2001), among others, have proposed explanations based on differences across individuals (ability, skills, and human capital) and the role played by generational transmissions (wealth and ability). Surprisingly, a powerful determinant of lifetime inequalities has not been considered. Indeed, Benabou (1993) shows the key role played by heterogeneity between locations in generating inequalities. However, Benabou's framework does not include a comprehensive theory of housing demand. As a consequence, an important determinant of inequalities which operates through the dynamics of prices across locations is missing. Indeed, there are potential large spillover effects between the outcomes of individuals in the labor, housing and education markets. Among these three markets, housing is the crucial determinant of lifetime inequalities by its importance in the household's portfolio and the bridge it builds between education and labor markets.

Motivated by these observations, I propose an overlapping generation model in the spirit of Bewley (1980), Huggett (1993) and Aiyagari (1994) as a unified framework for the analysis of inequalities. The standard life-cycle model is modified to allow for heterogeneous agents, a realistic housing market and aggregate uncertainty. This general framework allows to evaluate household behavior in a lumpy housing market with renting and owning. Moreover, heterogeneity between locations with respect to their level of social capital is included. ${ }^{1}$ The level of social capital in a location influences household labor productivity and the level of human capital of the next generation. The model allows for endogenous housing prices based on individual expectations. The price level affects the timing of homeownership and the set of locations in which it is possible for a given household to buy a dwelling. Furthermore, the expected price growth plays a significant role in the individual saving decision and location choice.

At a household level, the key mechanism underlying the model is the trade-off between the level of social capital and housing prices. For a given household, the level of social capital of its residential location influences labor productivity. Moreover, parents' transmission to their children operates through a bequest motive, but also through the impact of local social capital on children's human capital formation.

A large body of literature studies the relationship between children outcomes and the characteristics of their childhood neighborhood (see e.g Oreopoulos, 2003). I specify two mechanisms allowing location to affect children outcomes. First, education infrastructure differs across locations. This assumption captures the fact that educational attainments differ across locations not only because of the sorting on student ability but also as a matter of differences in schooling infrastructure. Second, the level of social capital in the neighborhood affects the human capital acquisition of the next generation. The

\footnotetext{
${ }^{1}$ In the literature, social capital is defined broadly as social cohesion, and personal investment into community. As a consequence, it refers to a notion of cooperation at a community level. I will use this broad concept to define how the well-being into a community affects the productivity of adults, and the human capital acquisition of children.
} 
heterogeneity in school quality between locations leads to differences in the next generation level of human capital. As a consequence, households have a higher preference for the neighborhood with the highest level of social capital, but some may be finance constrained due to the cost of a housing unit. The fixity of housing supply in each neighborhood combined with the borrowing constraints prevent some households from living in their preferred area, which leads to segregation and further strengthens inequalities.

Hence, the effects of borrowing constraints are reinforced by their implications not only for parents but also children. This form of borrowing constraint is more appealing than in the existing literature since households should be allowed to borrow not only against their future income but also against the future income of their children.

For empirical purpose, a unique dataset that provides information on individual characteristics (Census Data), income and wealth (Wealth Surveys), housing prices (Housing Surveys) and the spatial differences over locations (Censuses) is created for France. On the methodological front, this paper contributes to the literature by matching the nonparametric kernel distribution simulated by the model to the data. This more demanding approach in terms of computation provides a more accurate representation of the distribution.

This benchmark allows to run several experiments to assess whether or not a voluntary policy can decrease the level of inequalities.

This paper contributes to the literature by providing a unified framework that encompasses all the transmission channels of inequalities (wealth inheritance, transmission of ability, role of capital market imperfections, spatial inequalities). In the model, neighborhood features are important determinants of both short-run and long-run inequalities. Using a general framework where the interactions between housing, labor and education markets are represented, I can bring together several parts of the literature which are inherently close but were diverging until now. On the one hand, the literature on segregation provides several pieces of evidence on the impact of neighborhoods in the generation of cross-section inequalities (see e.g. for racial segregation Cutler and Glaeser, 1997; Bajari and Kahn, 2005 and for income stratification Epple and Sieg, 1999). On the other hand, an extensive body of literature tries to decompose lifetime inequality (Castaneda et al., 2003; Huggett et al., 2011 and Piketty, 2000 for an emphasis on social capital).

The rest of this paper is organized as follows: in the first section, the related literature is presented. In the second, the model and the computation strategy are presented. In the third, the data are presented with an emphasis on the spatial and life-cycle dimension of the variables of interest. In the fourth section, I present the results and their implications. Finally, several policy experiments are simulated. 


\section{Previous Literature}

The existing literature on inequalities focuses on two topics: the decomposition of lifetime inequalities, and the determinants of wealth concentration. ${ }^{2}$ In this section, I focus on the determinants of lifetime inequalities and the macroeconomic literature that tries to mimic wealth distribution.

First, the sources of lifetime inequalities have been extensively analyzed. Some findings from Keane and Wolpin (1997), Storesletten et al. (2004) and Huggett et al. (2011) are summarized. The question is to quantify respectively the share of lifetime inequalities that can be attributed to differences in initial conditions and to shocks received over lifetime. Among all these models, Keane and Wolpin (1997) are the only one to consider structural estimation. Keane and Wolpin (1997) estimate a realistic model of career choice for a sample of young men. They find that differences across individuals realized at age 16 accounts for approximately $90 \%$ of the variance in lifetime utility. These results contrast with the work of Storesletten et al. (2004) who attributes to initial conditions only half of lifetime inequalities. Finally, in a recent paper, Huggett et al. (2011) study the same question allowing for three sources of differences across individuals: initial human capital, learning ability and financial wealth. The results demonstrate that variation in initial conditions accounts for approximately $61.5 \%$ of lifetime earnings. Unfortunately, these models lack a mechanism explaining the formation of initial conditions.

Second, an important macroeconomic literature tries to reproduce the wealth distribution using OLG models. Earlier references include Huggett1993 and Aiyagari (1994) on the role of aggregate uncertainty. Recent literature extends in two directions: allowing for productivity shocks (Krusell and Smith, 1998) and bequest (de Nardi, 2004). Krusell and Smith (1998) make a significant contribution to the literature. They extent the basic dynastic models to allow for aggregate shocks. The motivation builds on the need to understand how the level of inequalities responds to income shocks. The model fits well the Gini index of wealth distribution. de Nardi (2004) provides new insights using a life cycle model with intergenerational transmission of genes and altruistic bequests. The model builds upon Heer (2001) and adopts a richer earnings process. The model fits extremely well the US wealth distribution.

However, this literature on inequalities puts a lot of effort trying to mimick the wealth distribution without paying attention to the deep process that generates inequalities. To overcome this, here, the generic model of inequalities is brought with the large and growing literature that analyzes the aggregate behavior of economies with heterogeneous agents, incomplete markets, aggregate uncertainty and a realistic housing market. In this literature, Iacoviello and Pavan (2009) develop a life-cycle model with lumpy housing prices and heterogeneity in household's productivity to study the debt over life-cyle. On a more empirical side, Li and Yao (2007) construct a life-cycle model of housing tenure choice to study the impact of housing price changes on household consumption and welfare. Li et al. (2009) estimate a

\footnotetext{
${ }^{2}$ The reader interested in dynamics of wealth concentration should take a look at Kopczuk and Saez (2004) for the US, Piketty et al. (2006) for France, and Dell et al. (2005) for Switzerland.
} 
structural model of housing consumption to identify the role of different factors in the explanation of the life-cyle properties of housing. Silos (2007) analyzes the relationship between the tenure choice of an individual and the composition of its portfolio. However, the reach of this literature is limited by the absence of an endogenous price formation mechanism. An alternative modeling strategy considers housing as an additional competitive sector in dynamic stochastic general equilibrium (see e.g. Davis and Heathcote, 2005 and Fisher, 2007). Prices are derived from a construction sector. However, this literature does not consider heterogeneous locations although it is well know in urban economics, that the price of a dwelling depends on its location and the characteristics of the neighborhood it belongs to (Ioannides, 2010). As a consequence, the previous models are not able to generate static differences in housing prices over locations and heterogeneity in their evolution over time. As will be shown in the following, heterogeneous locations allow to understand simultaneously the dynamics of spatial and overall inequalities and how they are related over time.

\section{Model}

The economy analyzed in this paper is a modified version of the standard OLG model with heterogeneous agents and heterogeneous locations. ${ }^{3}$ The key features of the model are as follows: (i) it includes a large number of households who are altruistic toward their descendants; (ii) agents are heterogeneous with respect to their age, idiosyncratic ability, human capital and wealth; (iii) households live in different locations; (iv) each location is ruled by a local government while the economy is ruled by a federal government; (v) locations are heterogeneous with respect to the level of social capital; (vi) the level of social capital affects the productivity of adults and the human capital acquisition of children; (vii) agents make mobility choice in a realistic housing market; (viii) the capital market is not perfect; as a consequence, some households may be finance constrained; (ix) agents face an uninsured idiosyncratic risk of unemployment; $(\mathrm{x})$ individuals inherited bequest from their parents and transmit wealth to their heirs. $^{4}$

\subsection{Household preferences}

There is a continuum of measure 1 of agents indexed by $i \in[0 ; 1]$ and time is discrete. Let's denote by $a$ the age of an individual. Individuals are born at age $a=20$, live at most $T$ periods, work until $\tilde{T}$. $\theta$ denotes the deterministic probability to survive from age $a$ to $a+1$. Therefore the distribution of agents over age $\Pi_{a}$ is stationary. At birth, each agent draws its family size and the timing of the birth.

There is a large number of locations denoted $n \in \mathcal{N} \equiv\{1, \ldots, N\}$. Each neighborhood has an

\footnotetext{
${ }^{3}$ In the rest of this paper, I will assume that a household is composed of a representative adult with or without children. I use the terms "households", "agents" and "individuals" interchangeably.

${ }^{4} \mathrm{~A}$ summary of the subsequent notations used is available in appendix.
} 
endogenous level of social capital denoted $z$. The total social capital is fixed with $\Pi_{Z}$ being the unique invariant measure, therefore it is only its allocation over neighborhoods that changes over time.

Each household has an ability denoted $j \in \mathcal{J} \subset[\underline{J}, J]$ which is revealed at age 20 . The level of human capital, specific to each household, is denoted $w \in \mathcal{W} \equiv[\underline{W}, W]$ which is acquired from age 20 to 21 . The level of human capital of an agent depends on his birth neighborhood $\tilde{n}$, and his ability $j$.

Households receive utility from the consumption of two goods, the non-durable good and the housing services. In addition, households value the human capital and the bequest of the next generation.

A typical household chooses its housing consumption level $h \in \mathcal{H}$ in order to maximize its utility:

$$
\begin{aligned}
u\left(c_{a}, h_{a}, n\right) & =u\left(c_{a}, h_{a}\right)+\varsigma w\left(j^{f}, i_{n}, z_{n}\right) & & \text { If } \mathrm{a} \leq 55 \\
u\left(c_{a}, h_{a}\right) & =u\left(c_{a}, h_{a}\right) & & \text { If } \mathrm{a}>55
\end{aligned}
$$

Where $\varsigma$ is the parent's degree of altruism towards her children. $w\left(j^{f}, i_{n}, z_{n}\right)$ is the human capital acquisition function which depends on the child's ability $j^{f}$, social capital infrastructure $i_{n}$ and the level of social capital $z_{n}$ in neighborhood $n$. To reconcile the model with reality, it is assumed that for their children's human capital acquisition process, parents value the quality of their neighborhood ten years before and ten years after the birth of their children.

Such a utility function encompasses the case with no intergenerational transfer when $\varsigma=0$. The age specific instantaneous CRRA utility corrected by family size at age $a, \Gamma_{a}$, is

$$
u\left(c_{a n}, h_{a n}\right)=\frac{\left(\left(\frac{c}{\Gamma_{a}}\right)^{1-\sigma}\left(\frac{h}{\Gamma_{a}}\right)^{\sigma}\right)^{1-\gamma}}{1-\gamma}
$$

Individuals can not borrow except for buying a house. The total savings of an individual is given by $-b$, and its total liability is given by $b$. These savings are invested into a risk-free asset which pays a gross interest $R=1+r$. All firms can borrow at this rate.

\subsection{Labor Market}

The specification of the labor market is similar to that in Lucas and Prescott (1974). Hence, each period, employed individuals draw a layoff probability $\vartheta$, while unemployed workers draw a hiring probability $\lambda$. The wage rate is fixed, as a consequence the only source of heterogeneity in total wage is the level of productivity.

The household labor productivity given by $l_{a j z w}$ can be decomposed between the contributions of: age $l_{a}$, social capital in his current neighborhood $l_{z}$, ability $l_{j}$ and human capital $l_{w}$. 
Let's assume that the wage per unit of labor supply is $\varpi$, and income is taxed at a proportional rate $t_{y}$. Hence, the individual net income is given by

$$
y=e .\left(1-t_{y}\right)\left(\varpi l_{a j z w}\right)+(1-e) \cdot d
$$

Where $e$ is the labor market status, which is 1 if employed and 0 else. $d$ is after tax unemployment benefit.

This simple specification of the labor market introduces aggregate uncertainty and the related insurance problem.

\subsection{Housing Market}

The housing supply is fixed in each neighborhood:

$$
H(n)=\bar{H} \quad \forall \quad n \in N
$$

Housing is a dual good: households can either rent (only consume housing services) or buy a dwelling (invest in housing and consume the housing services). The tenure is summarized by the dummy $\iota$ which is equal to 1 if the household is homeowner and 0 otherwise. Housing as an asset depreciates at rate $\delta_{h}$. The real estate agencies (REA) play the intermediary role in every transaction. The introduction of the REA improves the fluidity of the housing market, and avoid waiting-list phenomenon in the housing market. In addition, we assume that only REA can be landlords i.e households can not own more than one house.

The price of a rental unit in neighborhood $n$ is given by $q_{n}$. A selling unit in the neighborhood $n$ is evaluated at price $p_{n}$. Owner-occupiers and landlords must respectively pay a property tax $t_{p}$ and $t_{p r}$, while renters pay a residential tax $t_{r}$. Households can decide to adjust their housing consumption. There is no adjustment cost for renters whereas homeowners incur a transaction cost of selling $\tau_{h}$ which is proportional to the value of the house.

When a household wants to buy a house, she may be subject to the imperfection of the capital market. In the literature, financial constraints are introduced as a limitation in the amount an individual can borrow against his future income. Applications include Kiyotaki and Moore (1997), Yang (2009) and Iacoviello and Pavan (2009). ${ }^{5}$ In this framework, a downpayment constraint is assumed

$$
-b \geq \kappa p_{n}
$$

This form of borrowing constraint is consistent with the French institutions which relies heavily on

\footnotetext{
${ }^{5} \mathrm{~A}$ household can not borrow more than its expected earnings. This is ensured by the transversality condition.
} 
individual capacity to refund.

REA are risk-neutral and borrow at the interest rate $r$ to buy any available dwelling. An immediate consequence of the risk neutrality of REA is that rental units consist of apartments not sold. Hence, in the most appreciated location, there is a mechanic effect that drives up the share of homeowners in the most appreciated neighborhood.

The real estate industry is competitive and pays taxes on its net income and capital gains. The perfect competition yields a zero profit condition that describes the relationship between rents and prices:

$$
q_{n}=\left(\delta_{h}+t_{p r}+\frac{r}{1+r}\right) p_{n}-\frac{1}{1+r} E\left(p_{n_{t+1}}-p_{n} \mid n\right)
$$

This relation defines the usage cost of an owner-occupied housing unit.

\subsection{Production}

In this economy, there is a large number of firms located in different neighborhoods. However, I assume that a representative firm exists, which maximizes its total profit. The production function is given by :

$$
Y_{t}=F\left(K_{t}, L_{t}\right)=K_{t-1}^{\alpha} L_{t}^{1-\alpha}
$$

where $K$ is the aggregate capital stock and $L$ is the stock of working efficiency labor units in the entire economy. Capital depreciates at rate $\delta_{K}$. Given the aggregate consumption $C$, government spending $G$, the aggregate resource constraint is :

$$
Y=C+G+K_{t+1}-\left(1-\delta_{K}\right) K
$$

\subsection{Government Budget Constraint}

There are two levels of governance in the model: a federal government at the economy level and a local government at the neighborhood level. Each government operates a redistribution. The federal government collects taxes on labor earnings and assets revenues to pay for unemployment benefits and the rest of the revenue is redistributed to the neighborhoods proportionally to their population size. The local government collects proportional taxes on property and renting. This cash flow allows to pay for the education infrastructure.

The objective is to not give a strategic role to the government, therefore its behavior is given.

\section{$2.6 \quad$ Timing}

Let's describe the timing of the model: 
- At the beginning of the period $t$, a measure $(1-\theta)$ of households die

- The heirs pay off any accidental debt and collect any bequest

- A measure $\theta$ of agents survive

- The households decide to move or to stay. If a household decides to move, she has to sell her former housing unit $h_{t}$ and chooses its tenure $\iota_{t+1}$, its housing and goods consumption $h_{t+1}, c_{t+1}$ and its wealth level $b_{t+1}$. If she decides to stay, she will choose $c^{\prime}$ and $b_{t+1}$

- $K_{t}$ and $L_{t}$ are supplied

- Wage, interest income and taxes are paid. Consumption and housing services are consumed

- The neighborhood-specific job arrival rates, and job destruction rates are revealed.

- Some agents are born

- Observe the birth neighborhood and the corresponding level of social capital $z$, and human capital infrastructure $i^{f}$

- Observe its ability

- Acquire human capital

- Become adults the next period, and leave their parents' home.

- Some agents retire

- The retired agents do not value anymore the level of social capital of their location. A housing adjustment may happen.

The model does not keep track of children development. It is assumed that parents value the characteristics of their location 10 years before and ten years after the birth of children. As a consequence, when young adult leave their parents home at age 21, the parents continue to value the characteristics of the neighborhood the 9 following years. ${ }^{6}$

\subsection{Locational Equilibrium}

In a locational equilibrium, households sort across neighborhoods along the dimensions on which they differ. In contrast to the literature on equilibrium local jurisdictions (Epple and Platt, 1998; Epple et al., 1993), the fixity of housing supply in each neighborhood induces a higher degree of stratification.

Definition: Consider a set of neighborhoods, $n=1, \ldots, N$. An allocation of households across neighborhoods is an equilibrium only if:

\footnotetext{
${ }^{6}$ It is assumed that agents are born at age 20 and become adult after one year. This assumption simplifies the dimension of the state variables and avoids to keep track of households over a long period of time. However, this simplification is not realistic. As a consequence, It is assumed that parents value the characteristics of the location 10 years before the birth of the children and 10 after this birth.
} 
1. The static housing choices are optimal i.e each household maximizes its housing consumption subject to the budget constraint.

2. The local housing markets clear.

\subsection{The Household Problem}

At period t, the set of individual state variables is: $w_{t}$ the household human capital, $j_{t}$ its ability, $z_{t}$ the level of social capital of the neighborhood it belongs to, $b_{t-1}$ the nonhousing wealth or debt, $h_{t-1}$ the housing stock owned former period, $\iota_{t-1}$ for tenure, $e_{t}$ for the labor market status and $a_{t}$ for age. Let's denote by $s_{t} \equiv\left(a_{t}, w_{t}, j_{t}, e_{t}, z_{t-1}, b_{t-1}, h_{t-1}, \iota_{t-1}\right)$.

Given initial condition, the household problem is to make a set of two choices: a mobility decision (move or stay), a tenure choice (rent or own).

Th dynamic problem of an agent with state variables $s_{t}$ is:

$$
V(s, \beta)=\max \left\{V^{s}\left(s_{t}, \beta\right), \sup _{z}\left\{V^{m r}\left(s_{t}, \beta\right)\right\}, \underset{z}{\sup }\left\{V^{m h}\left(s_{t}, \beta\right)\right\}\right\}
$$

under the constraint of the total resources of household $b^{t} . V^{s}, V^{m r}$ and $V^{m h}$ are respectively the value function if an agent stays, rents after a mobility and owns after a mobility.

\subsubsection{The value of staying}

An individual who decides to stay in its current housing unit can not adjust its consumption of housing. As a consequence, the choice set is reduced to consumption and saving. The value of staying is the solution to the following problem:

$$
\begin{aligned}
& V^{s_{t}}\left(s_{t}, \beta\right)=\sup _{c_{t}, b_{t}} \quad u(c, h, a)+\theta_{a} \beta E\left[V\left(s_{t+1}, \beta\right)\right] \\
& \text { s.t. } \quad y_{t}+b_{t}-\left[r b_{t-1}\left(1+t_{i b_{t-1} \geq 0}\right]\right) \geq c_{t}+\left[\iota\left[p_{n t}\left(t_{p}\right)\right]+(1-\iota)\left[q_{n}\left(1+t_{r}\right)\right]\right] h_{t} \\
& \quad c_{t} \geq 0 ; \quad h_{t} \geq 0
\end{aligned}
$$

Where $i b_{t-1} \geq 0$ is a dummy indicating that the household holds positive savings.

When an individual decides to move, she has to choose the location that maximizes its utility under its resource constraint. The index of the current location is $n_{t}$, while the next location is given by $n_{t+1}$.

\subsubsection{The value of moving and renting}

The value of moving and renting is the solution to the following problem: 


$$
\begin{aligned}
& V^{m r}\left(s_{t}, \beta\right)=\sup _{c_{t}, h_{t}, b_{t}, z_{t}} u\left(c_{t}, h_{t}, a\right)+\theta_{a} \beta E\left[V\left(s_{t+1}, \beta\right)\right] \\
& \text { s.t. } \quad y_{t}+b_{t}-\left[r b_{t-1}\left(1+t_{i b_{t-1} \geq 0}\right]\right)+\iota_{t-1}\left[\left(1-\tau_{h}\right)\left(1-\delta_{H}\right) p_{n_{t-1}} h_{t-1}\right] \geq c_{t}+\left[q_{n}\left(1+t_{r}\right)\right] h_{t} \\
& \quad c_{t} \geq 0 ; \quad h_{t} \geq 0
\end{aligned}
$$

\subsubsection{The value of moving and owning}

Finally, the value of moving and owning is the solution to the following problem:

$$
\begin{aligned}
& V^{m r}\left(s_{t}, \beta\right)=\sup _{c_{t}, h_{t}, b_{t}, z_{t}} u\left(c_{t}, h_{t}, a\right)+\theta_{a} \beta E\left[V\left(s_{t+1}, \beta\right)\right] \\
& \text { s.t. } \quad y_{t}+b_{t}-\left[r b_{t-1}\left(1+t_{i b_{t-1} \geq 0}\right]\right)+\iota_{t-1}\left[\left(1-\tau_{h}\right)\left(1-\delta_{H}\right) p_{n_{t-1}} h_{t-1}\right] \geq c_{t}+\iota_{t}\left[p_{n_{t}}\left(1+t_{p_{n_{t}}}\right)\right] h_{t} \\
& \qquad b \geq(1-\kappa) p_{n_{t}} h_{t} \\
& \quad c_{t} \geq 0 ; \quad h_{t} \geq 0
\end{aligned}
$$

\section{$2.9 \quad$ Bequest Motives}

Now, an explicit bequest motive is allowed. ${ }^{7}$ The main complication comes from the fact that it adds another term to the value function. Let's illustrate this by writing the value function of staying.

$$
V^{s}\left(s_{t}, \beta\right)=\sup _{c_{t}, b_{t}} u\left(c_{t}, h_{t}, a\right)+\theta_{a} \beta E\left[V\left(s_{t+1}\right)\right]+\left(1-\theta_{a}\right) \varsigma \psi\left(b_{t+1}+\iota\left(p_{n_{t+1}} \cdot h_{t}\right)\right.
$$

With all these concepts at hand, it is now possible to define an equilibrium.

\subsection{Competitive Recursive Equilibrium}

A recursive competitive equilibrium is a set of value functions $V\left(s_{t}, \beta\right)$, policy functions for the mobility decisions $M^{*}\left(s_{t}, \beta\right)$, the saving decision $B^{*}\left(s_{t}, \beta\right)$, the tenure choice $\iota^{*}\left(s_{t}, \beta\right)$, the level of social capital $Z^{*}\left(s_{t}, \beta\right)$, the consumption $C^{*}\left(s_{t}, \beta\right)$, and the wage rate $\varpi^{*}\left(s_{t}, \beta\right)$ for each age-level and aggregate variables $K_{t}, L_{t}, H_{t}^{h}, G_{t}$, level of taxes $\left\{t_{y}\right\},\left\{t_{i}\right\},\left\{t_{p}\right\},\left\{t_{r}\right\}$, prices $p_{n t}, q_{n t}$ for each period $\mathrm{t}$, and the joint distribution of all states $\Phi$ such that:

1. The locational equilibrium holds with respect to its former definition.

2. Given the housing prices in each neighborhood $\left(q_{n t}, p_{n t}\right)$, the wage rate $\varpi_{t}$ and the laws of motion

\footnotetext{
${ }^{7}$ In the former specification, any accidental bequest was collected by the local government.
} 
$\left(\pi^{K}, \pi^{L}\right): K^{*}$ and $L^{*}$ are determined competitively at any t

$$
\begin{gathered}
r^{*}+\delta_{k}=F_{K}\left(K^{*}, L^{*}\right) \\
\varpi^{*}=F_{L}\left(K^{*}, L^{*}\right)
\end{gathered}
$$

3. The unemployment rate is stationary, and the labor supply equals:

$$
L^{*}=\int l_{a j z w}(z, \beta) d \Phi_{t}\left(a, e, n, j, b_{t-1}, h_{t-1}, z_{t-1}\right)
$$

4. The asset market clears at any $\mathrm{t}$

$$
K^{*}=\int b^{*}+\left(\left[1-\iota^{*}\right] q_{n^{*}}^{*}-\left[1-t_{p}-\tau_{h}-\delta_{h}\right] p_{n^{*}}^{*}\right) h^{*} d \Phi_{t}\left(a, e, n, j, b_{t-1}, h_{t-1}, z_{t-1}\right)
$$

5. The distribution of bequest is stationary.

6. The rental price is given by the no-arbitrage condition in the real estate sector

$$
q_{n^{*}}^{*}=\left(\delta_{h}+t_{p}+\frac{r^{*}}{1+r^{*}}\right)-\frac{1}{1+r^{*}} E\left(p_{n_{t}}^{*}-p_{n_{t-1}}^{*} \mid n\right)
$$

7. The housing market clears in every neighborhood

$$
\bar{H}=H(n)=\int h_{n}^{*} d \Phi_{t}\left(a, e, n, j, b_{t-1}, h_{t-1}, z_{t-1}\right)
$$

8. The federal and local governments budgets constraint hold

$$
\begin{gathered}
G_{F}^{*}=t_{y} \varpi^{*} L^{*}+\int\left(t_{i} r^{*} b^{*}-d\right) d \Phi_{t}\left(a, e, n, j, b_{t-1}, h_{t-1}, z_{t-1}\right) \\
G_{L}^{*}=\frac{1}{N} G_{F}^{*}+\int\left(\iota h^{*} p_{n^{*}}^{*} t_{p}+(1-\iota) h^{*} q_{n^{*}}^{*} t_{r}\right) d \Phi_{t}\left(a, e, n, j, b_{t-1}, h_{t-1}, z_{t-1}\right)
\end{gathered}
$$

9. The distribution of the state variables $\Phi_{t}\left(a, e, n, j, b_{t-1}, h_{t-1}, z_{t-1}\right)$ is stationary.

\subsection{Solution Method}

The model has no analytical solution, thus I follow the literature and solve it numerically as in Heer (2001). However, there are some issues related to the housing dimension and the existence of heterogeneous locations. Since there is no aggregate production shocks, and we focus on the steady state of the model, the major computation issue of the model comes from the housing prices. The solution algorithm, 
described in appendix, tries to derive for each neighborhood a sequence of prices that equalizes demand and supply every period as in Lee (2005). The general solution algorithm for the model consists of the following steps:

Step 1: Make initial guesses of steady state values of the aggregate labor supply $L$ and the aggregate capital $K$.

Step 2: Guess an initial level of housing prices in every neighborhood and the corresponding rental price

Step 3: Given housing prices, labor productivity, and interest rate, compute the optimal decision functions by tenure, employment status, income levels, portfolio composition in each neighborhood

Step 4: Iterate backward in time $t=T_{c-1}, \ldots, 1$ and recover the sequence of housing prices and policy functions.

Step 5: Compute the optimal path for human capital investment, consumption, saving, employment, residential choices for the new-born generation.

Step 6: Compute the steady-state distribution of assets and bequests in each cohort-neighborhood

Step 7: Compute the aggregate capital stock K and Labor supply L

Step 8: Update K and L and return to step 3 until convergence

Before the first step, an optimal time horizon $T_{c}$, which is 300 years.

In step 3 and 4, a finite-time dynamic program is solved by iterating the policy functions of generation $t$ backward starting in the last period. The policy functions are computed from the Euler equation for each type of agents over a discrete grid. I can determine the optimal decision for period $t$ given period $t+1$ optimal controls in grid points. I use a cubic spline interpolation technique in order to get optimal decisions.

At step 6, the distributions of assets and bequests are recovered using the preceding values. I start the computation of the model based on data from the 1990 census, and iterate until reaching a steady state. I made an assessment of the model based on census data available in 1999, then I present the result derived from equilibrium. ${ }^{8}$

\section{Data}

The agents and the locations are heterogeneous along a large number of dimensions. I use the 1990 and 1999 French population censuses to characterize them. The population census contains extensive

\footnotetext{
${ }^{8}$ The solution of the model is very demanding in terms of computation. It takes 15 days CPU time on a Unix Workstation.
} 
information about employment, household composition, education, geographical location for one fourth of the population. The sample size allows to compute the precise individual characteristics at the suitable geographical level and provides a full picture of the housing market. In the empirical analysis, a neighborhood is an IRIS, the French equivalent to the US census blocks.

Using two samples allows to construct a mobility matrix between locations over a period of 10 years. A notable limitation of the French census is the absence of financial information. That is, wealth, income and housing prices are missing. The following strategy is used. First, the distribution of income (moments) over space can be obtained from an administrative source, Revenus Fiscaux des Menages. This distribution can be computed at the finest geographical level (IRIS). Then, the first two moments (mean and standard deviation) can be used to draw an income for each household depending on its neighborhood.

The information about wealth comes from two wealth surveys: Actifs 92 and Patrimoine $2004 .^{9}$ However, the limited sample size per neighborhood does not allow to characterize the full distribution of assets. To overcome this, I assume that the distribution of wealth across and within a neighborhood is three times as volatile as the income distribution.

Finally, housing prices data comes from the 1992, 1996 and 2002 French Housing surveys. A mean price by square meter is computed for each transaction. However, the number of neighborhoods present in the two samples is limited. In the final sample, only 1,006 neighborhoods with all the required variables are considered. These neighborhoods are located in the 30 biggest French metropolitan areas. In order to reduce the computational burden, only a fifth of the 1999 census data is considered. This yields a total sample size of 500,588 individuals with the neighborhood population ranging from 290 to 1,106 .

\subsection{Descriptive Evidence}

I start by describing the life-cycle dimension of the basic variables. Let's start by family size over the life-cycle using the 1999 census.

As expected, the family size follows an inverse U shape that is consistent with the patterns of family composition over the life-cycle. The family size reaches its maximum size around 40 years, and then decreases.

It is now insightful to look at the similarities between family size and homeownership. The Figure 2 plots the rate of homeownership as a function of age.

The share of homeowners in the population increased from $53.8 \%$ in 1992 to $56.0 \%$ in 2002. This rise is driven by the persistence of a high homeownership rate for individuals older than 60 . However, Figure 2 missed the decrease in the flow of new homeowners that started after 1996.

\footnotetext{
${ }^{9}$ Since 1986, the French Statistical Office (INSEE) have carried out a survey on Wealth every six years. It was called Actifs Financiers until 1992, before becoming Enquete Patrimoine in 1998.
} 
Figure 1: Family size over the life cycle

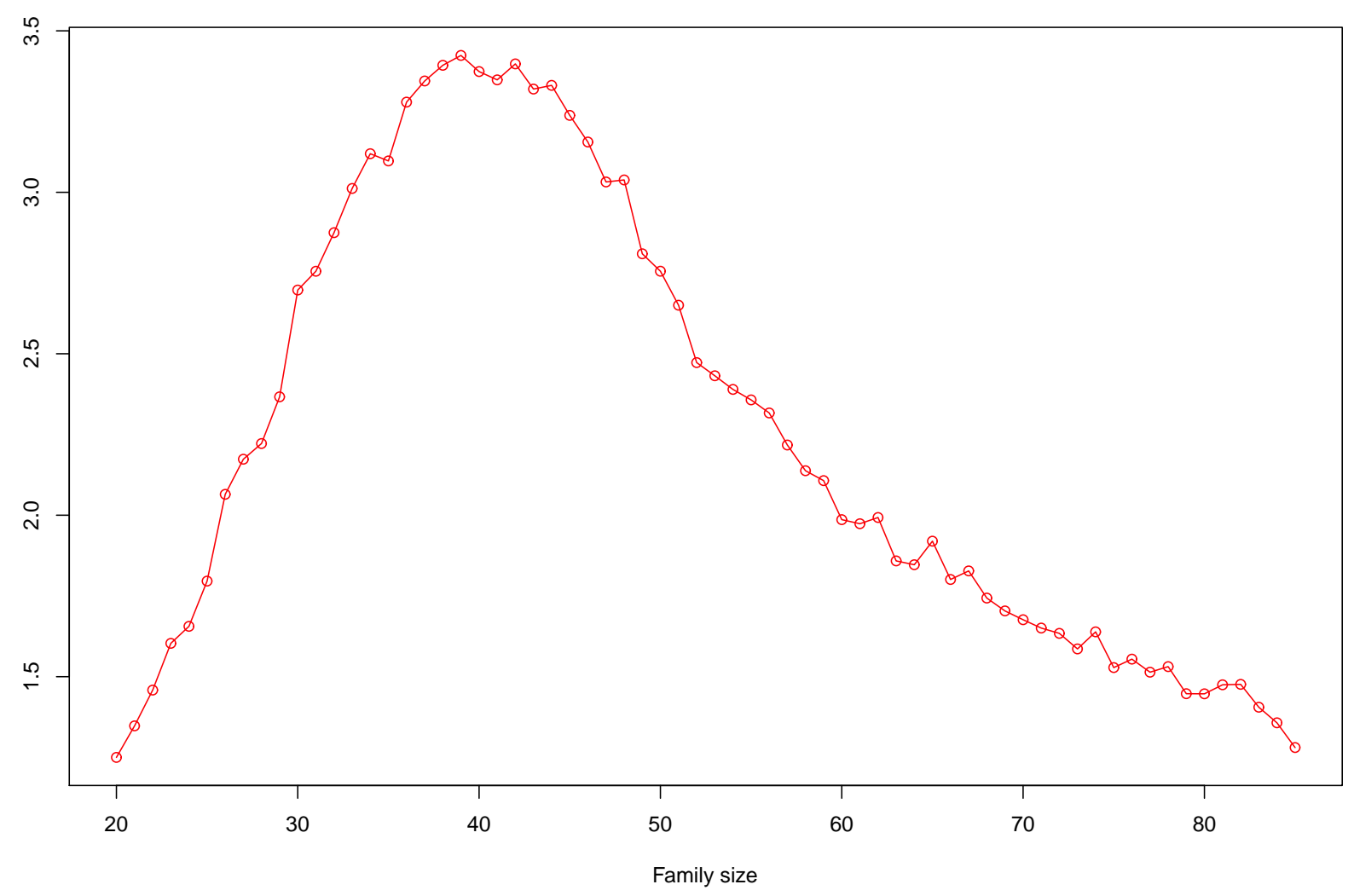

Regarding the labor market, Figure 3 plots the unemployment rate over the life-cycle in 1992 and 2002. I record an unemployment rate of $10.5 \%$ in 1993, and $8 \%$ in 2002. The differences between the two distributions reflect this discrepancy.

The distribution of housing wealth over the life-cycle is now analyzed. There is a large discrepancy between the housing stock detained by French households over the period from 1992 to 2004. The most plausible explanation is related to the increase in the general level of prices. ${ }^{10}$

Some basic facts about intergenerational transfers are documented based on the wealth surveys 1992 and 2004. There is a large discrepancy between the transmission behavior in 1992 and 2004. That is, only $5 \%$ of the households perceived a donation in 1992, while the rate is close to $20 \%$ in 2004 . The same holds for inheritance, only $18 \%$ of households declared an inheritance in 1992, while the rate is close to $40 \%$ in 2004. These discrepancies may reflect changes in the thresholds for the taxation of inheritance. In terms of amount, it is complicated to provide a comparison over time since the amount are presented by ranges, and the categories are not constant over time. To overcome this, the more homogeneous 1998 and 2004 Wealth surveys are used to provide some facts about generational transfers. Table 1 shows the

\footnotetext{
${ }^{10}$ Because of the small sample size, the data shows several inconsistent spikes.
} 
Figure 2: Homeownership over the life-cycle (Housing Surveys)

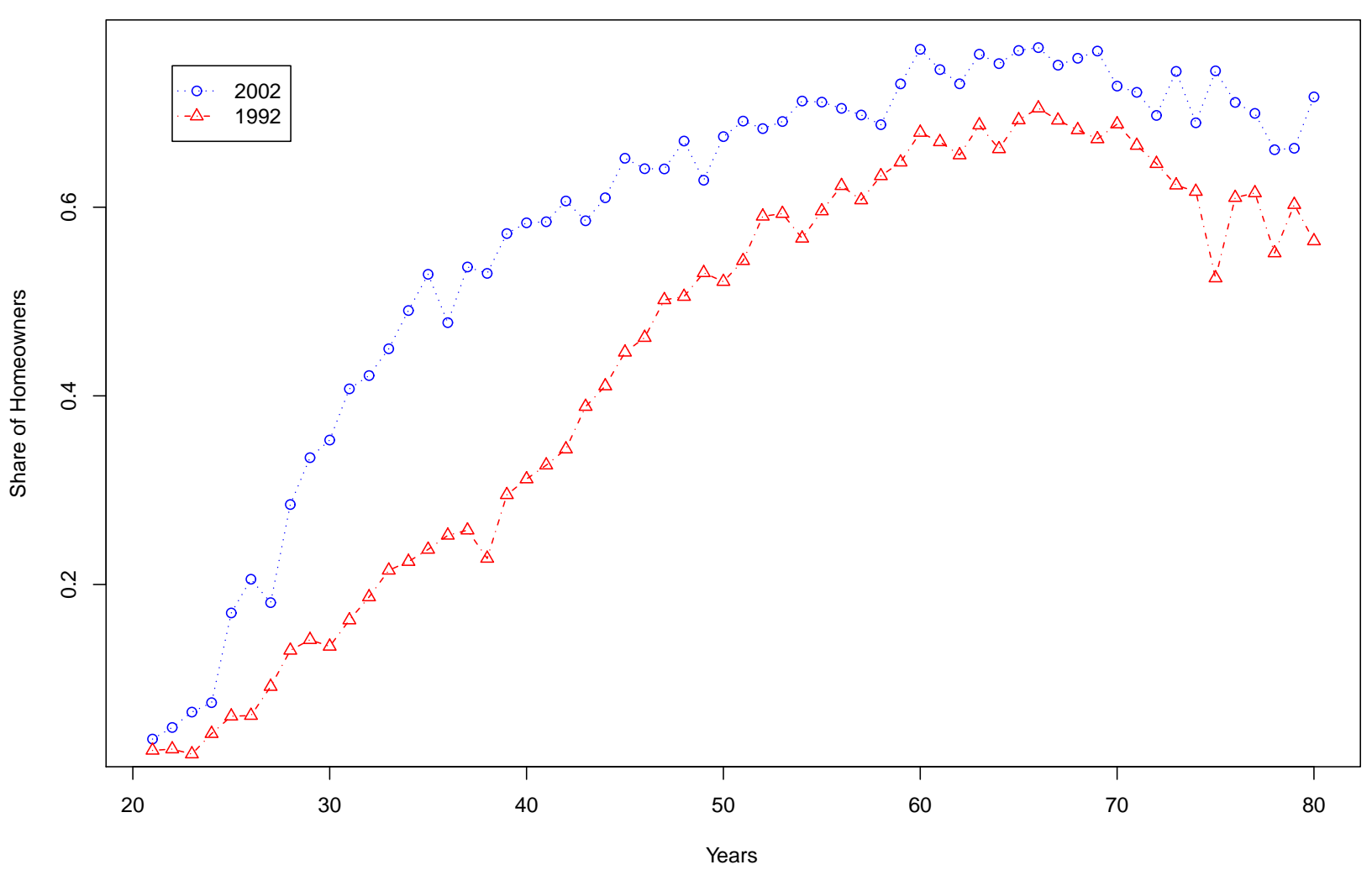

evolution of the share of bequest in individual wealth. For more than half of the population, $60.3 \%$ in 1998 and $58.3 \%$ in 2004, there has been no inheritance yet. Two important facts need to be pointed out in terms of dynamics. First, the share of individuals who did not benefit from inheritance or did not inherit a negligible amount decreases over time while the share of individuals who benefit from a substantial share of their total wealth increases.

Table 1: Share of inheritance between 1998 and 2004

\begin{tabular}{lcc}
\hline Share & 1998 & 2004 \\
\hline No inheritance & 60.3 & 58.3 \\
Null & 8.6 & 7.7 \\
Less than $25 \%$ & 18.2 & 18.5 \\
From 25 to $50 \%$ & 6.7 & 7.4 \\
More than $50 \%$ & 5.5 & 6.8 \\
\hline Notes: Sources: Patrimoine 1998, 2004. Number of observations: 10,207 in 1998 \\
9,239 in 2004
\end{tabular}

Data are completed with the findings of Piketty (2011) who reports around $10 \%$ of national wealth transferred across generations. These transmissions are not uniformly distributed. In 1994, the top $10 \%$ generational transmissions represented $55 \%$ of the total transfers across generations. 
Figure 3: Unemployment over the life-cycle (Labor Surveys)

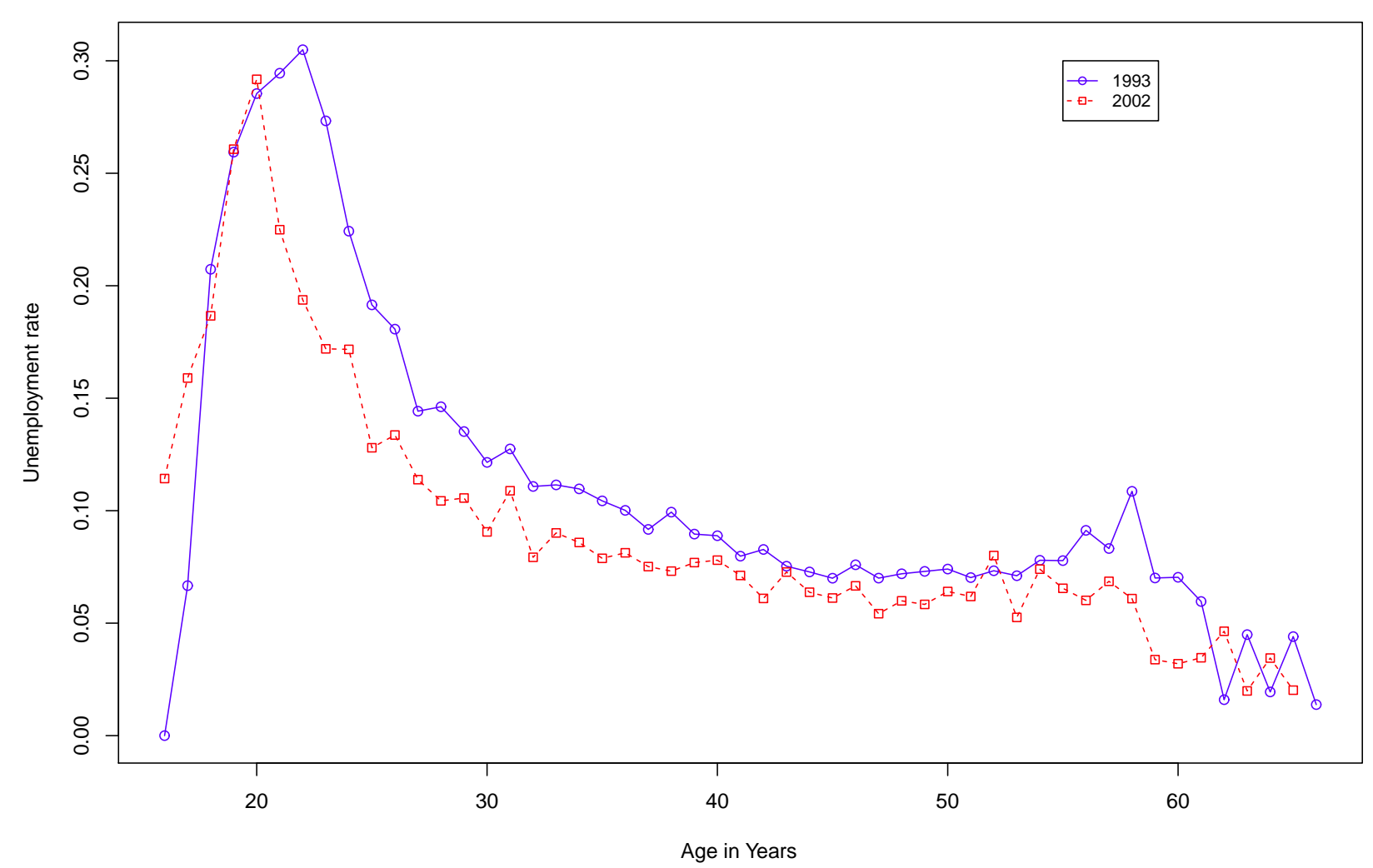

After having described the life-cycle dimension, the distribution of some basic characteristics over space can be analyzed.

Both homeownership and unemployment rates are very spread across locations. Table 3.1 reports the distributions. More surprisingly, given the existence of mandatory education in France, the level of individuals with no degree per neighborhood is also very spread moving $2.3 \%$ to $43.2 \%$ revealing a high level of sorting. Finally, the level of housing prices ranges from $249.5 €$ in the municipality of Denain in the North of France to $9,147 €$ in the $7^{\text {th }}$ district of Paris.

Table 2: Descriptive Statistics over neighborhoods (Census 1999 and 2002 Housing Survey)

\begin{tabular}{lllll}
\hline & Minimum & Mean & Sd & Maximum \\
\hline Share of homeowners & 1.2 & 49.7 & 19.6 & 95.2 \\
Share of unemployed & 4.2 & 12.1 & 5.7 & 50.2 \\
Share of individuals with no degree & 2.3 & 13.1 & 6.8 & 43.2 \\
Share of individuals with college education & 1.1 & 9.9 & 2.8 & 17.2 \\
Price by square meter in 2002 in $€$ & 249.5 & 1,542 & 831 & 9,147 \\
\hline
\end{tabular}

Notes: Sources: Census 1999, Housing Survey. The analysis uses the observations from the 30 biggest metropolitan areas. 
Figure 4: Housing wealth over the life cycle (Wealth Surveys)

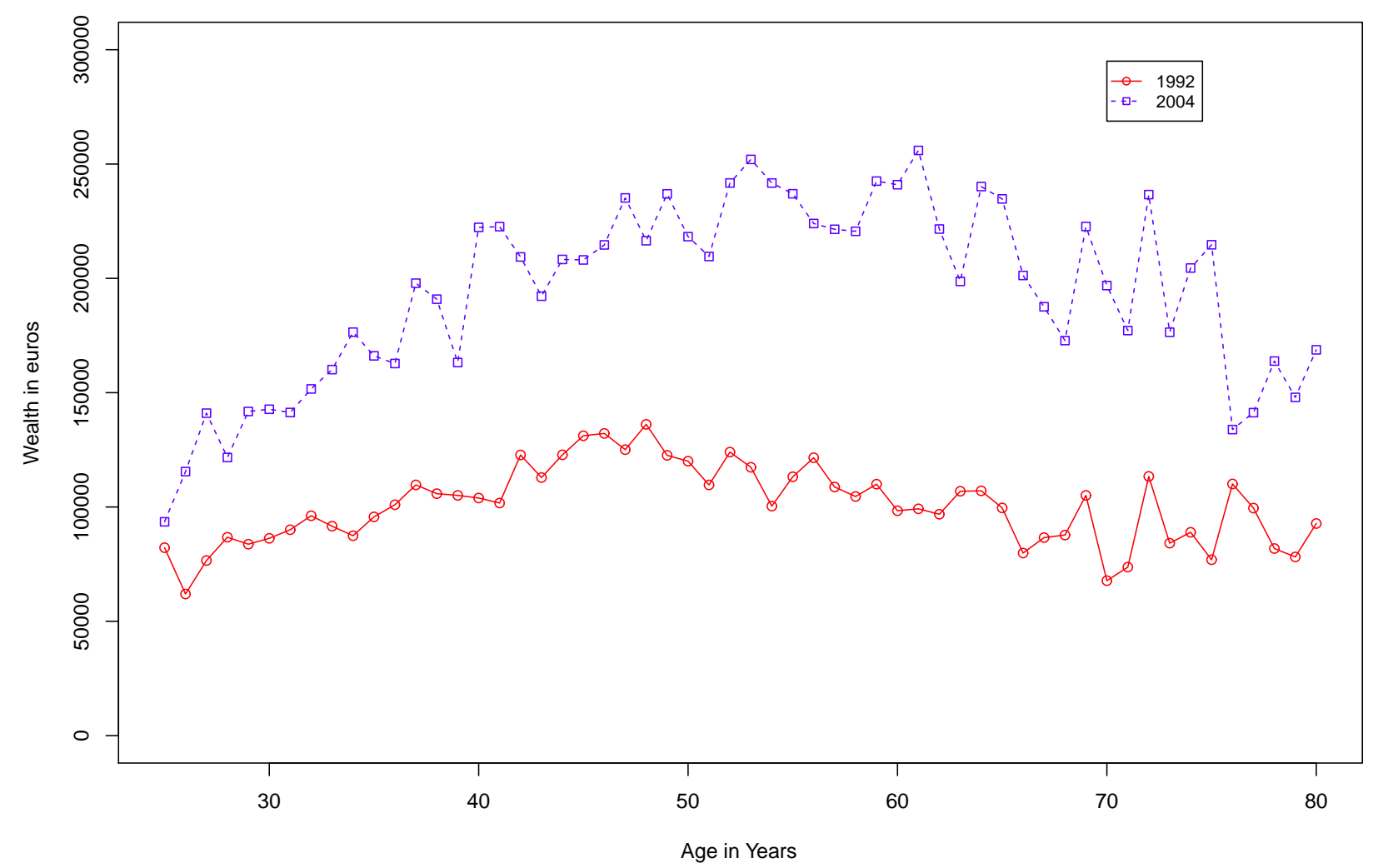

\section{Results}

In the model, the households choose consumption, saving and make residential choices. I consider for now the model when individuals do not have a bequest motive i.e any bequest is collected by the local government. As displayed in Figure 5, the model fits until age 65, and does not perform well in predicting the homeownership rate after retirement. Indeed, agents over consume both goods and housing services without holding any housing asset. This is due to the fact that the prospective increase in price combined with the lower usage cost of homeownership does not compensate for the level of transaction and maintenance costs.

Instead of recalibrating the parameters, I move directly to the model where agents have a bequest motive which provides much more interesting results.

\subsection{Homeownership Over The Life-cycle}

The model fits extremely well the homeownership rate over the life-cycle. In 2002, the model predicts an homeownership rate of $54.6 \%$ to be compared to $54.2 \%$ in the data. According to the analysis, 
Figure 5: Homeownership over the life cycle (Results)

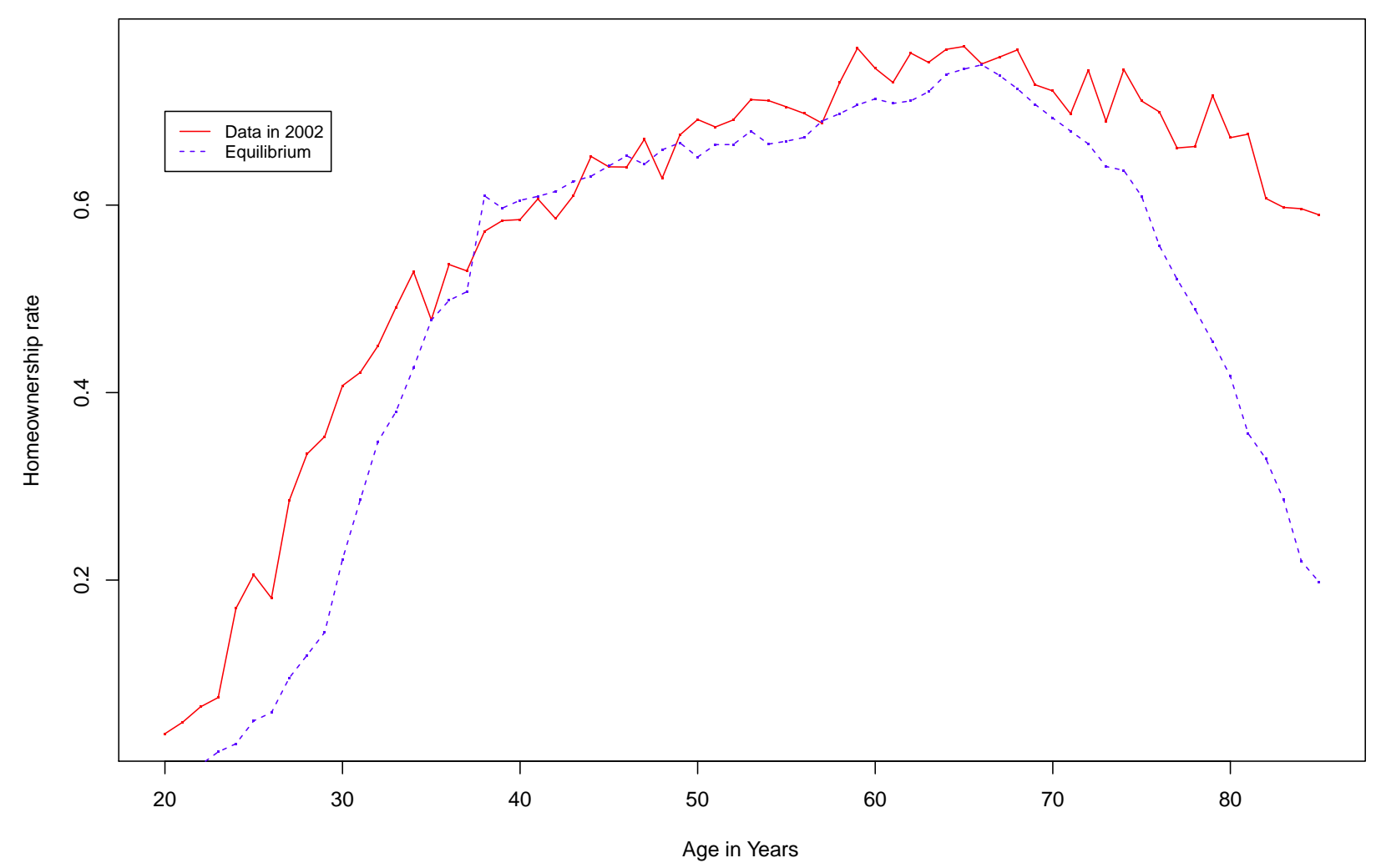

the equilibrium homeownership rate is approximately $50.2 \%$ which is substantially lower than the last available homeownership rate, $57.8 \%$ in 2009 . Moreover, the homeownership rate has been increasing since the early 2000. As a consequence, the housing market may be running on a disequilibrium path. ${ }^{11}$ The effect of the predicted slowdown in the homeownership rate is not uniform across life-cycle. Indeed, the equilibrium homeownership rate is almost always lower than in the data except for the range of ages higher than 70. The presence of bequest plays a decisive role in generating this result as explained in the preceding section.

\subsection{Prices and Social Capital over Locations}

Prices and the level of social capital in equilibrium are now analyzed. Figure 7 displays the equilibrium prices (in $1 / \mathrm{K} €$ ) and level of social capital against their values in the data. In equilibrium, both the level of prices and social capital are much more spread to the right than in the data. This indicates a higher dispersion, and a widening of inequalities across neighborhoods.

Table 3 reports the moments of the former distributions. Equilibrium and initial prices display strong

\footnotetext{
${ }^{11}$ Our model does not include the favorable institutional environment set up to promote homeownership after 1996 . A free interest rate loan was set up in 1996 for low-income household.
} 
Figure 6: Homeownership over the life cycle (Results)

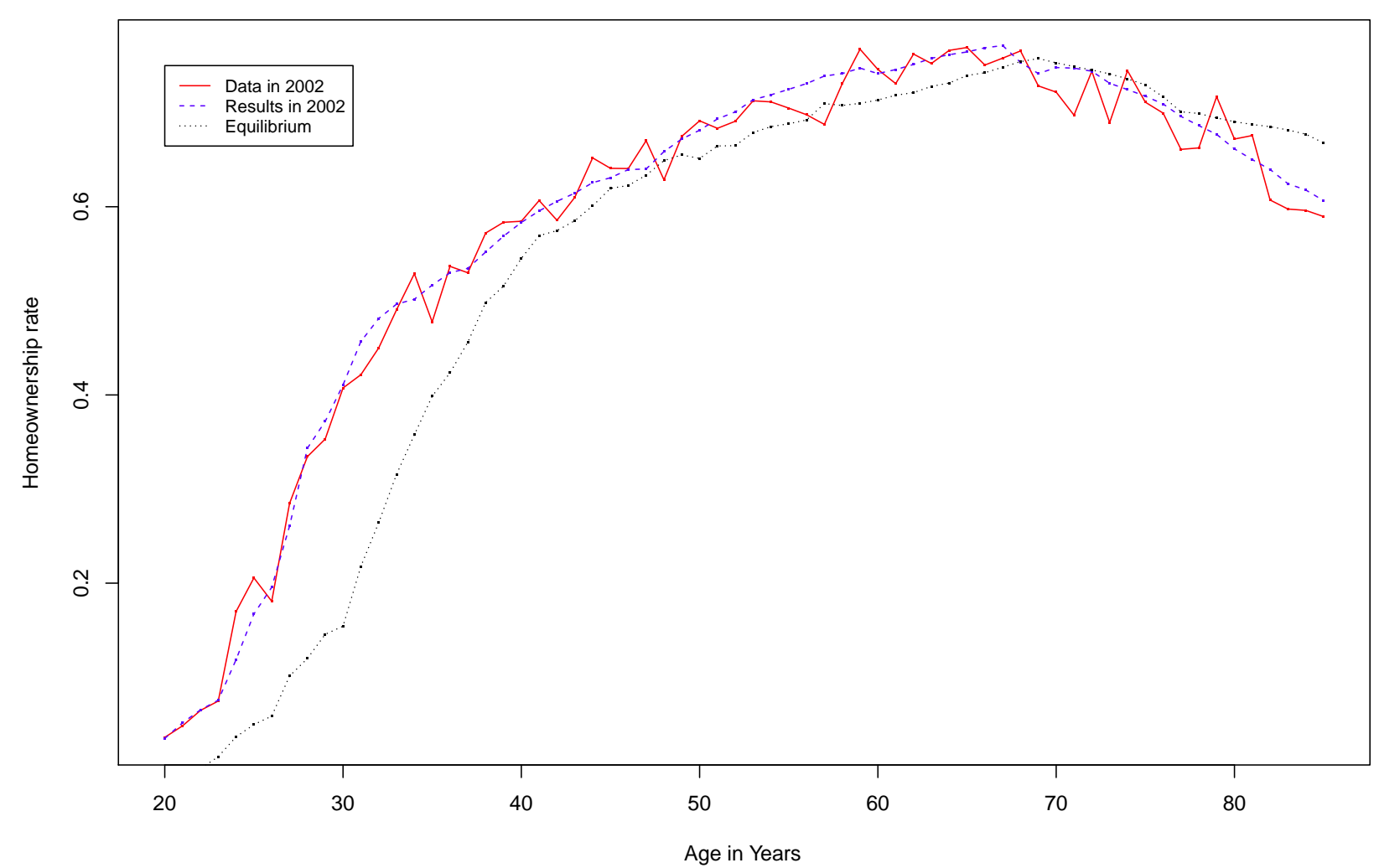

distributional differences. The first quarter and the median of the equilibrium prices are respectively 0.08 and 0.12 whereas these quantiles are equal to 0.10 and 0.13 in the data. The large dispersion of the equilibrium prices yields a standard deviation of 0.21 to be compared to 0.08 in the data.

Table 3: Prices and social capital distributions

\begin{tabular}{lccccccc}
\hline & \multicolumn{7}{c}{ Moments and Quantiles } \\
& Min & $1^{\text {st }}$ Qu. & Median & Mean & Std dev. & $3^{\text {rd }}$ Qu. & Max \\
\cline { 2 - 8 } Price (Data) & 0.0249 & 0.1001 & 0.1343 & 0.1542 & 0.0831 & 0.1829 & 0.9147 \\
Prices (Equilibrium) & 0.2011 & 0.0828 & 0.1205 & 0.2015 & 0.2119 & 0.1832 & 1.090 \\
Social capital (Data) & 0.2397 & 0.4381 & 0.4909 & 0.4932 & 0.0826 & 0.5473 & 0.7712 \\
Social capital (Equilibrium) & 0.0504 & 0.3250 & 0.4008 & 0.4464 & 0.1787 & 0.5088 & 0.9346 \\
\hline
\end{tabular}

The same shift happens with the level of social capital. As a consequence, the equilibrium relation between prices and the level of social capital exhibits stronger correlation than in the initial period. That is, the initial correlation that the model matched was around 0.17 whereas in equilibrium, correlation is approximately 0.76. To sum up, there is a higher level of price discrimination in equilibrium. The related mechanism is driven by the competition for the best neighborhoods which drives up the level of prices. This leads to the concentration of characteristics positively correlated to social capital in the best 
Figure 7: Nonparametric density of the distributions of prices and social capital

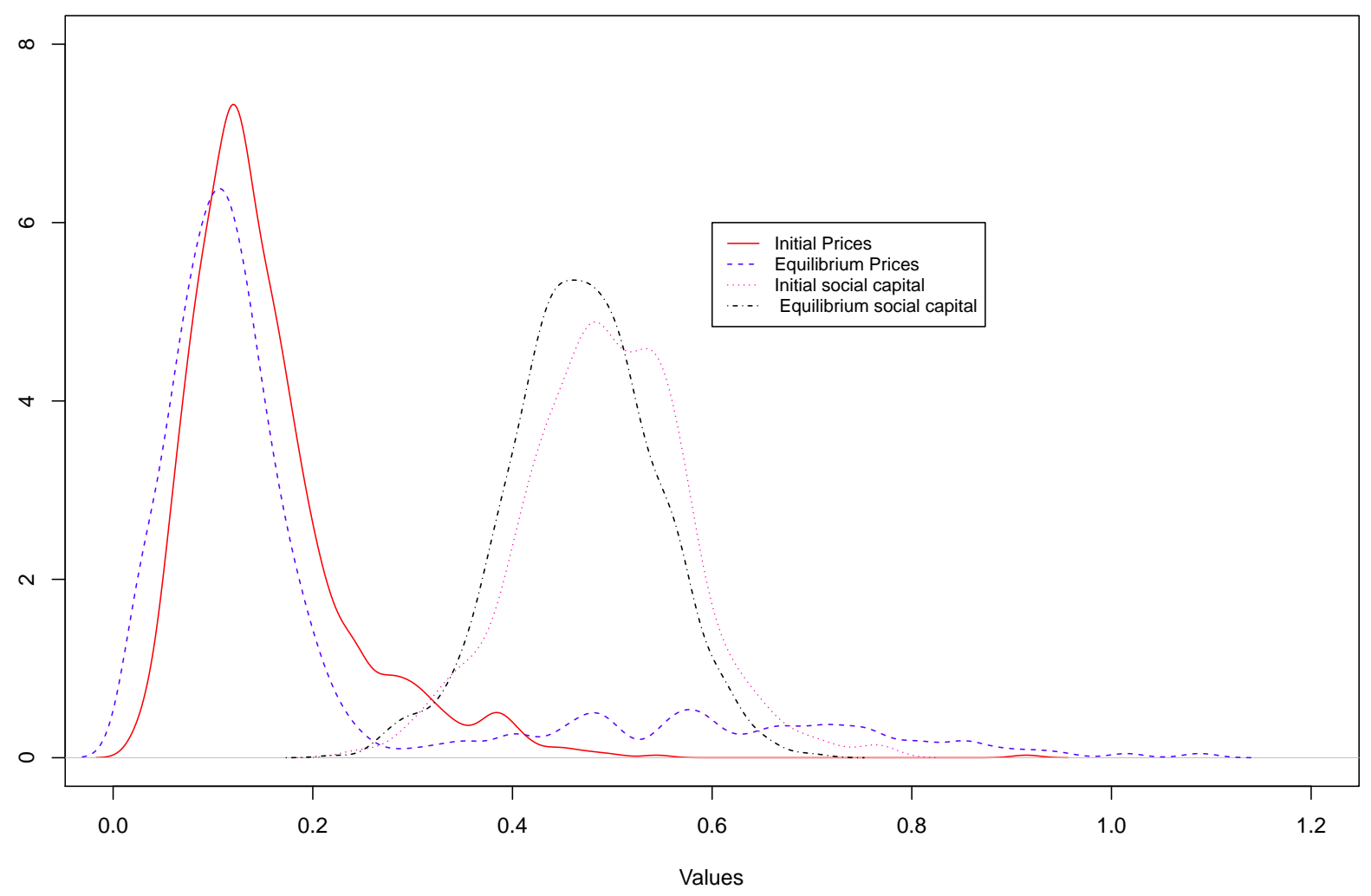

locations. This self-enforcing mechanism is the main determinant of these results. This result in terms of sorting reflects the equilibrium of the model, and are derived from the initial conditions provided by data.

\subsection{Unemployment Over The Life-cycle And Between Locations}

The outcome of the model in terms of unemployment is shown in Figure 8. The calibration of the job offer rate assumes skill-specific job arrival rate. The model fits very well the unemployment rate over the life cycle. However, there are some distributional differences between the simulated equilibrium and the data. In equilibrium, the unemployment rate is much lower for young people (less than 30 years) than in the data. Conversely, the equilibrium unemployment rate is higher for individuals between 60 and 65 years old than in the data. This result is driven by the dynamics of inequalities. As disparities across individuals and locations widen, the job arrival rate for this class of individuals, which was low in our baseline calibration, does not adjust. As a consequence, the unemployment rate increases. Table 4 summarizes the differences between locations. An unforeseen outcome is related to the highly polarized distribution of unemployment. While in the data, only 5 neighborhoods have an unemployment rate 
lower than 5\%, in equilibrium, there are 122 such neighborhoods. Likewise, only 3 neighborhoods in the data have an unemployment rate higher than $40 \%$ whereas in equilibrium there are 141 neighborhoods in this case. The increase in the disparities between neighborhoods is explained by the high segmentation according to the level of social capital.

Figure 8: Unemployment over the life cycle (Results)

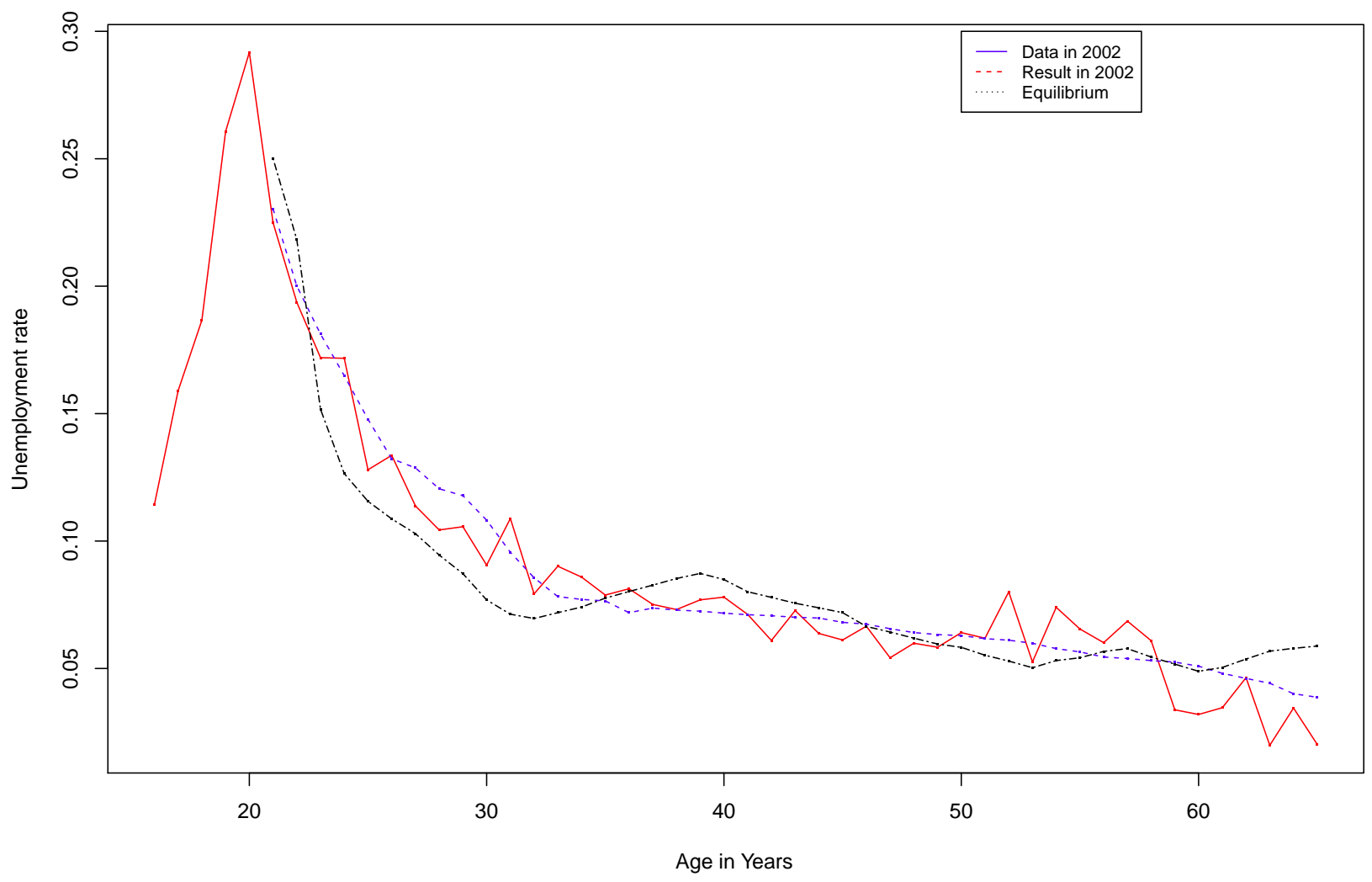

Table 4: Unemployment per age and locations

\begin{tabular}{lccccccc}
\hline & \multicolumn{9}{c}{ Moments and Quantiles } \\
& Min & $1^{\text {st }}$ Qu. & Median & Mean & Std dev. & $3^{\text {rd }}$ Qu. & Max \\
\cline { 2 - 8 } Local Unemployment (Data) & 0.0422 & 0.0891 & 0.1119 & 0.1276 & 0.0575 & 0.1529 & 0.4981 \\
Local Unemployment (Model) & 0.0119 & 0.0633 & 0.0878 & 0.1595 & 0.1773 & 0.1160 & 0.9204 \\
\hline
\end{tabular}

The former results are confirmed by the nonparametric estimation of the distribution of unemployment over locations. Two pieces of evidence can be drawn from Figure 9. On one hand, the distribution presents a spike at a very low unemployment rate, around $4 \%$. On the other hand, another peak of a smaller magnitude takes place around $50 \%$. 
Figure 9: Nonparametric density of unemployment rates over locations

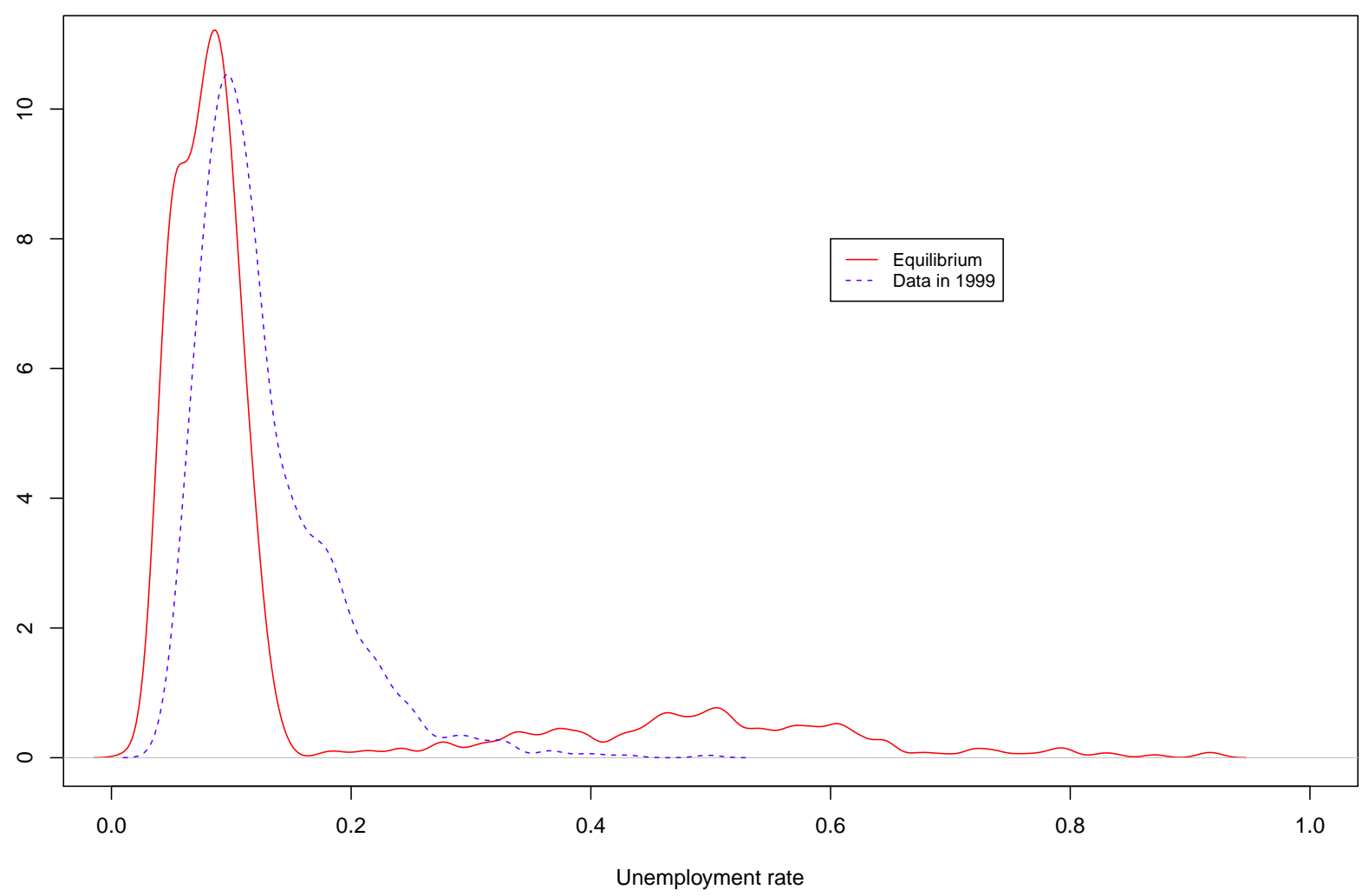

\subsection{Wealth and Intergenerational Link}

This section is devoted to the intergenerational link. Table 5 reports the characteristics of individuals at the bottom and the top of the wealth distribution. The ultimate goal is to examine the respective contributions of differences across generations, individuals and locations to overall inequalities.

Individuals at the bottom of the wealth distribution have hardly inherited $1 \%$ of their current wealth. Basically, these individuals have a tiny level of wealth, as a consequence, the amount of bequest is negligible. However, there is a great deal of endogeneity explaining this outcome. Due to the low level of social capital in their birth location, several individuals do not get a high education. As a consequence, their prospect in the labor market and in terms of wealth accumulation are slim. On the contrary, the richest individuals have a high share of bequest in their wealth. Bequests account for $88 \%$ of the wealth of the individuals in the top percentile. These individuals have a lower level of education and ability than their counterpart belonging to the $10 \%$ and $5 \%$ percentiles. Overall, differences in the level of social capital in the birth neighborhood explain a substantial part of inequalities over generations.

Another implication of the model is related to intergenerational mobility. Basically, individuals at the bottom of the wealth distribution, are those with the lowest social capital at birth. In equilibrium, 
Table 5: Wealth distribution, inheritance and individual characteristics

\begin{tabular}{lllllll}
\hline \hline & Bottom & Bottom & Bottom & Top & Top & Top \\
& $1 \%$ & $5 \%$ & $10 \%$ & $10 \%$ & $5 \%$ & $1 \%$ \\
\cline { 2 - 7 } Inheritance (\%) & 0.2 & 0.7 & 1.2 & 69 & 81 & 88 \\
Ability & 0.44 & 0.56 & 0.60 & 0.73 & 0.61 & 0.58 \\
Education & 9.1 & 12.3 & 13.4 & 17.6 & 15.8 & 15.2 \\
Social capital & 0.09 & 0.12 & 0.16 & 0.55 & 0.76 & 0.87 \\
Social capital at birth & 0.07 & 0.13 & 0.15 & 0.49 & 0.59 & 0.89 \\
\hline
\end{tabular}

$21.3 \%$ of individuals live in a better neighborhood than their parents at retirement age. This suggests a much lower rate of intergenerational mobility than in the study of Blanden et al. (2002) who estimate this ratio to be around $60 \%$ in the UK. Even if they do not report results for France, one could expect an intergenerational mobility at least similar to the one in the UK. Given the current trends in wealth concentration, the results bring new light into the long-term consequences of such a phenomenon.

\section{$5 \quad$ Extensions and Experiments}

\subsection{Extensions}

At this point, lifetime inequality is decomposed between individuals, locations and generational components. The model is simulated with a single source of heterogeneity at a time. I start with a cohort of individuals born in the same neighborhood and who receive later the same amount of bequest. Ability is the only source of heterogeneity in this case. ${ }^{12}$ Then, I simulate a cohort of homogeneous individuals in terms of ability and born in the same location. The only source of heterogeneity is the amount of bequest. Finally, the differences in the level of social capital are analyzed. Using these three simulations, the lifetime inequality can be decomposed over the contributions of individuals differences, initial endowment and locations heterogeneity. This simulation exercise used a sample of 100,000 with all the source of inequality distributed as in the steady state of the model.

In the long-run, bequest and spatial inequalities account for approximately $80 \%$ of lifetime inequalities. Heterogeneity in individual ability accounts for around $18.2 \%$, while bequest represents $55 \%$ of wealth inequalities. Unfortunately, there is to my knowledge no paper in the literature with the same sources of inequalities that could be used as a benchmark for comparison.

These results shed new light on the dynamics of inequalities. In the recent period, several reports demonstrate that wealth disparities across individuals have widened. For example, the 2010 French Wealth Survey reports that the discrepancy in wealth between the top $10 \%$ and the bottom $10 \%$ of households has increased by $35 \%$ from 2004 to 2010 with housing prices as the main driving force. In a context of widening inequalities between generations and locations, we show clearly that in the long run

\footnotetext{
${ }^{12}$ The individual component of inequality could have been measured using the level of education. However, since education depends on the level of social capital of the birth neighborhood, it is more suitable to use the idiosyncratic ability.
} 
the major determinants of inequalities are bequest and differences across locations.

Table 6: The decomposition of wealth inequalities

\begin{tabular}{lcccc}
\hline \hline & Ability & Bequest & Social Capital & Education \\
\cline { 2 - 5 } After 10 years & 52.3 & 8.5 & 40.2 & 62.4 \\
After 20 years & 38.1 & 25.2 & 36.7 & 48.9 \\
After 30 years & 29.9 & 36.5 & 33.6 & 42.3 \\
After 40 years & 25.1 & 44.3 & 29.6 & 36.8 \\
After 50 years & 18.2 & 55.0 & 26.8 & 31.5 \\
\hline
\end{tabular}

\subsection{Experiments}

After having highlighted the importance of bequest and spatial inequalities in the differences across individuals, the effects of some policies on overall inequalities is simulated. These policies are based on institutional measures and taxes. In the first experiment, the borrowing constraints are relaxed. In the second, bequest taxation is imposed. Finally, the last experiment implements a policy against income segregation that will constraint every neighborhood to have a diverse population in terms of education. ${ }^{13}$

\subsubsection{No borrowing constraints}

Table 7: The effects of borrowing constraints

\begin{tabular}{lcccccccc}
\hline \hline & \multicolumn{7}{c}{ Age distribution } \\
Outcomes & $21-30$ & $31-35$ & $36-40$ & $41-45$ & $46-50$ & $51-64$ & $65+$ \\
\hline \multirow{2}{*}{ With Borrowing Constraints } \\
Homeownership & 6.8 & 31.1 & 48.8 & 58.9 & 64.2 & 67.6 & 71.7 \\
Education & 13.9 & & \multicolumn{7}{c}{0} & & \\
Social capital & 0.21 & 0.33 & 0.39 & 0.42 & 0.46 & 0.53 & 0.47 \\
\cline { 2 - 8 } & \multicolumn{7}{c}{ Without Borrowing Constraints } \\
\cline { 2 - 9 } Homeownership & 15.8 & 34.6 & 52.1 & 60.9 & 67.5 & 70.2 & 74.8 \\
Education & 14.2 & & & & & \\
Social capital & 0.23 & 0.32 & 0.41 & 0.44 & 0.47 & 0.52 & 0.45 \\
\hline
\end{tabular}

There are several potential channels under which borrowing constraints could affect the behavior of agents. The most obvious one is related to the homeownership decision. Several other channels exist. First, the borrowing constraint of the parents can affect the level of education of the children. Second, it can delay the homeownership decision of the young individuals and prevent them from living in the best neighborhoods. The results shows that all these channels are effective. First, there is a substantial effect on homeownership. The mean homeownership rate without borrowing constraint is around $62 \%$ to be compared to $54 \%$ in the presence of borrowing constraint. This effect holds for the younger generations. It increases also both the mean and the dispersion of housing wealth in the population. In fact, an indirect consequence of relaxing borrowing constraints is on the level of prices. As shown in Figure 10,

\footnotetext{
${ }^{13}$ I use interchangeably the terms melting pot, urban mix, diversity to refer to an administrative policy that imposes a share of low educated to each location.
} 
the equilibrium distribution of prices is much more spread on the right with the mean price moving from $2015 €$ per square meter in the model with borrowing constraints to more than $3400 €$ per square meter when borrowing constraints are relaxed. This sharp increase is mainly due to the highly inelastic demand for the best neighborhoods. As a consequence, the number of neighborhoods with a mean price higher than $5,000 €$ per square meter increases substantially from 126 to 280 .

Figure 10: Nonparametric density of the price distribution

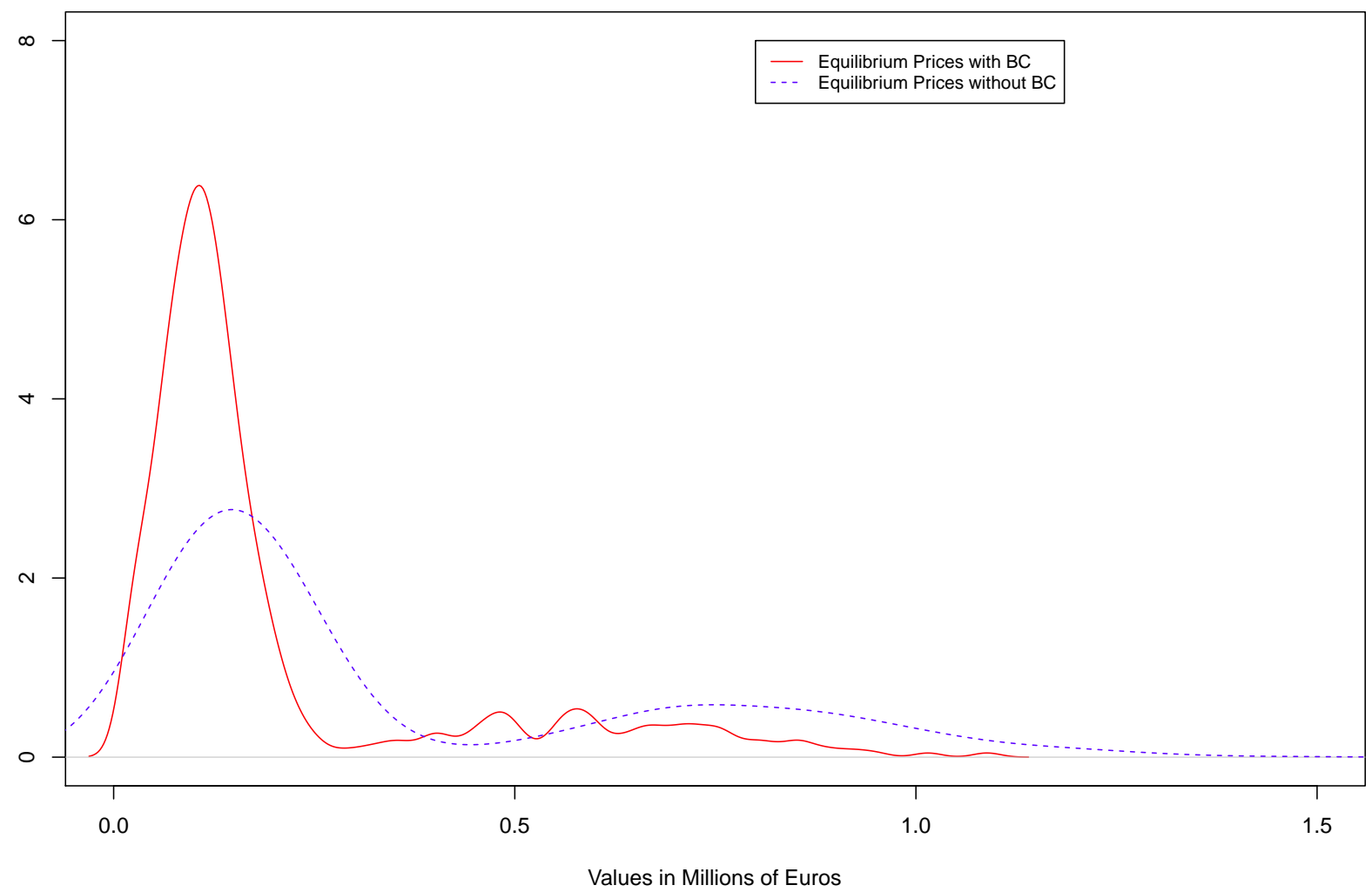

Additional implications are in terms of social capital and education. There is a small distributional effect on the level of social capital of the youngest agents, allowing them to buy in better neighborhoods than what they could do otherwise. Finally, borrowing constraints have an effect on the distribution of education. The mechanism is related to the increase in the level of housing prices which yields higher tax revenues for the government. The consequence is an appreciation in the level of human capital acquisition infrastructure. The mean education rate increases from 13.9 to 14.2 . However, this effect holds only for the inhabitants of the neighborhoods with the highest level of social capital. To sum up, relaxing borrowing constraints is effective in helping young individuals achieving homeownership. However, because of several undesirable consequences (prices, education), the net effect on well-being is not clear. 


\subsubsection{Bequest taxation}

The introduction of a tax on bequest has an important impact of the wealth transmission behavior of agents. It should be noted that the effect is highly dependent of the taxation rate. A taxation of $100 \%$ is similar to the model with no bequest. The results are similar but of smaller magnitude for the range of taxation rates higher than $60 \%$. These levels of taxation act as a disincentive to wealth accumulation and transmission, but provide more resources to the local governments. Since, the majority of bequests happens in the best neighborhoods, the ultimate consequence is to increase disparities across locations via the education institutions which are financed by local tax revenues. ${ }^{14} \mathrm{~A}$ potential solution would be to assign the bequest to the federal government. This solution creates a better redistribution and increases the mean educational level. Still, there are lot of inefficiencies due to overconsumption after retirement.

The most interesting cases occur for a taxation rate between 10 to $30 \%$. There is still overconsumption, but of a smaller magnitude, and the induced mobility stabilized both the level of price and the homeownership rate. Table 8 reports the distributions of the share of inheritance, ability and education of individuals located in the tail of the wealth distribution. The effect of age is accounted for by using a cohort of individuals.

A comparison between these numbers with those Table 5 demonstrates that the mean educational level and the mean ability level of the most wealthy individuals tend to increase, highlighting the shift toward a society more fair and the decreasing role inheritance in inequalities.

Table 8: Wealth distribution, inheritance and individual characteristics

\begin{tabular}{|c|c|c|c|c|c|c|c|}
\hline \multirow{2}{*}{\multicolumn{2}{|c|}{$\begin{array}{l}\text { Taxation } \\
\text { Rate }\end{array}$}} & \multicolumn{6}{|c|}{ Top and Bottom groups (Percentile) } \\
\hline & & Bottom & Bottom & Bottom & Top & Top & Top \\
\hline \multirow{4}{*}{$10 \%$} & & & & & & & \\
\hline & Inheritance $[0: 100]$ & 0.1 & 0.6 & 0.9 & 56 & 69 & 76 \\
\hline & Ability $[0: 1]$ & 0.43 & 0.58 & 0.63 & 0.76 & 0.67 & 0.61 \\
\hline & Education $[9: 20]$ & 11.4 & 13.2 & 13.1 & 18.5 & 17.7 & 16.8 \\
\hline \multirow{3}{*}{$15 \%$} & Inheritance & 0.1 & 0.5 & 0.8 & 45 & 51 & 63 \\
\hline & Ability & 0.44 & 0.57 & 0.68 & 0.76 & 0.70 & 0.66 \\
\hline & Education & 11.4 & 12.9 & 13.7 & 17.6 & 17.4 & 17.5 \\
\hline \multirow{3}{*}{$20 \%$} & Inheritance & 0.1 & 0.4 & 0.8 & 40 & 46 & 57 \\
\hline & Ability & 0.41 & 0.49 & 0.58 & 0.79 & 0.72 & 0.70 \\
\hline & Education & 11.3 & 12.1 & 13.4 & 18.1 & 17.9 & 17.6 \\
\hline \multirow{3}{*}{$25 \%$} & Inheritance & 0.1 & 0.3 & 0.8 & 36 & 41 & 55 \\
\hline & Ability & 0.42 & 0.52 & 0.60 & 0.78 & 0.71 & 0.71 \\
\hline & Education & 11.8 & 12.6 & 13.9 & 18.3 & 18.0 & 17.9 \\
\hline \multirow{3}{*}{$30 \%$} & Inheritance & 0 & 0.3 & 0.7 & 32 & 38 & 49 \\
\hline & Ability & 0.43 & 0.51 & 0.57 & 0.79 & 0.72 & 0.73 \\
\hline & Education & 11.8 & 13.1 & 13.8 & 18.4 & 17.9 & 17.9 \\
\hline
\end{tabular}

\footnotetext{
${ }^{14}$ After retirement, the location of an individual has no impact on its well-being. As a consequence, the high rate of bequest taxation drives to a large share of individuals selling their home in the best neighborhoods and renting in the cheapest ones. These individuals over-consume both housing services and consumption and end up with a small amount of wealth.
} 
The mean level of education is highly dispersed across taxation rates. The minimum level of education tends to increase with the level of taxation as one would have expected since education is financed by local tax revenues. However, since the model assumes stationarity in the level of social capital, and given its importance in education, the assumption prevents the mean education from increasing over time. The share of inheritance in total wealth decreases substantially with higher taxation rate, particularly for the most wealthy individuals. This decrease is compensated by a higher share of highly educated individuals. However, since the level of social capital of the birth location is a determinant of the level of education, there is still a persistent component in the level of inequalities.

\subsubsection{Diversity}

The last policy consists of imposing to each location a minimum share of low educated individuals. I present the results with $15 \%$ of low educated individuals in each location. In Figure 11, the initial and equilibrium distributions of prices and social capital are plotted. The major effect is a reduction in the dispersion of both the level of prices and social capital. This policy acts as a bound to the average local social capital and holds back the growth of housing prices. Compared to alternative policies, this policy performs better because it softens the individual trade-off between neighborhoods. More precisely, it acts as a maximum level of social capital that prevents prices and homeownership rate to increase as they do in the basic model.

\section{Conclusion}

In this paper, I proposed a model to study the outcomes of the housing, labor and education markets when local interactions matter. This paper makes several contributions to the literature. First, to my knowledge, this is the first paper to analyze homeownership decision with endogenous prices not derived from a construction sector but from rational expectations on future prices accounting for neighborhood quality. It shows that bequest motive can explained the the saving decisions of the elderly highlighting a solution to the puzzle of Carroll (1997). Second, the heterogeneity of locations combined with the dynamics of prices provides a powerful tool for analyzing the dynamics of inequalities. Third, frictions in the labor market and imperfections in the credit market create an insurance problem. Saving acts as a self-insurance mechanism against negative shocks. The trade-off between bonds and housing assets allow individual to diversify their investment thanks to the presence of transaction costs in the housing market. Finally, the introduction of a bequest motive allows to investigate the dynamics of generational inequalities.

The results show that the model performs well in explaining several stylized facts. A decomposition of the lifetime inequality demonstrates that bequest accounts for a sizable part of lifetime inequality, 
Figure 11: Prices and social capital with urban mix

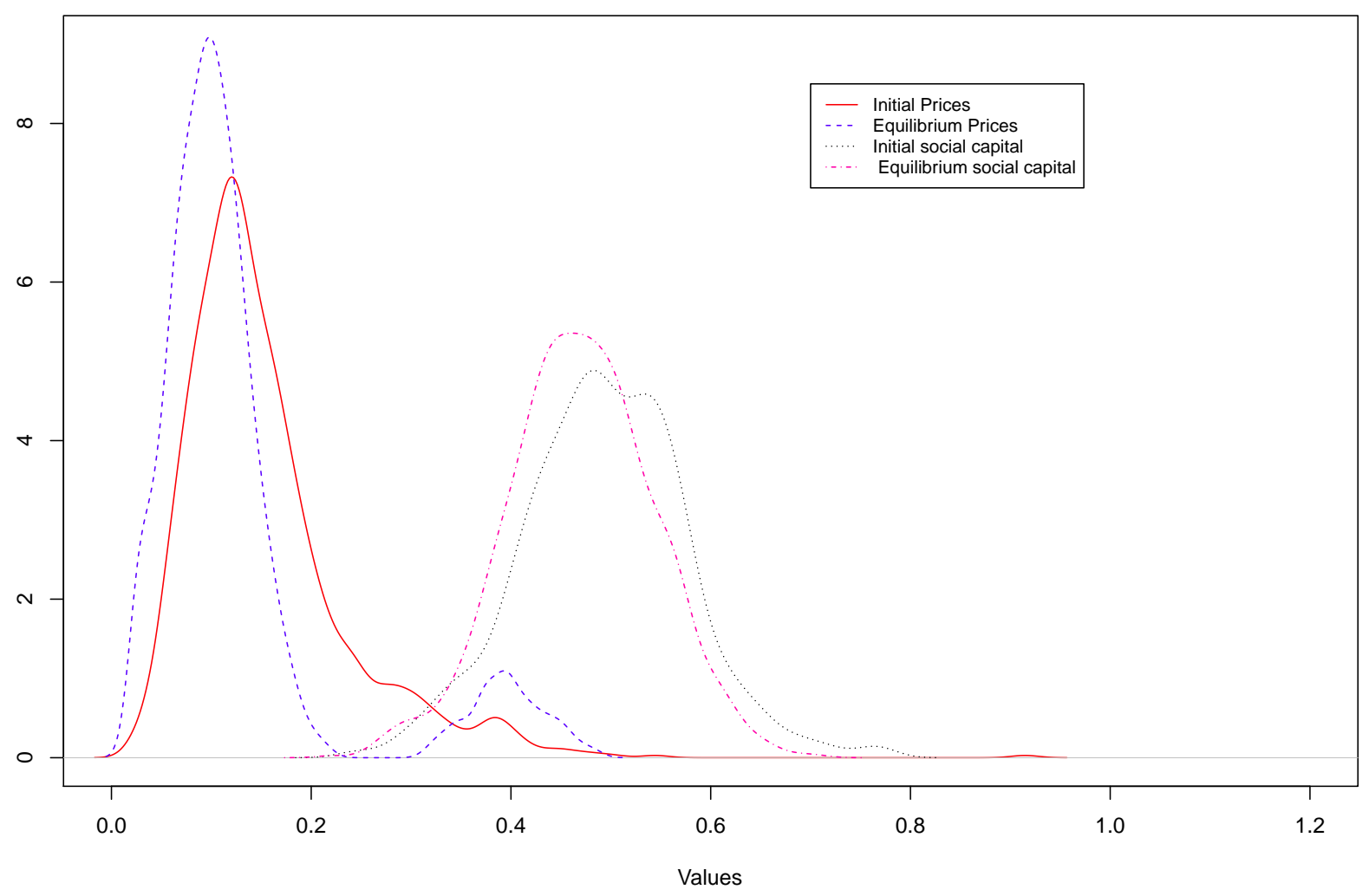

while the spatial inequalities account for approximately $25 \%$ of the overall inequalities. I carry several experiments using the model. One of the most interesting result is related to the consequences of relaxing borrowing constraints. The main consequence of such a policy is to increase the level of prices. This outcome may be the explanation of the level of housing prices observed in the majority of the developed countries before the 2008 crisis. Among all the policies considered, a mix of bequest taxation and diversity policy would provide an efficient control for the level of spatial and generational inequalities. In practice, it may be argued that a policy of diversity is hard to implement. One should note that a similar policy exists in France. Instead of imposing a share of low educated individuals, it imposes to each location a minimum share of public housing. For a policy maker interested in decreasing lifetime inequalities, this is a good starting point.

Although the model presents several advantages, the results are subject to several modeling simplifications. First, the model does not consider education as a choice variable. A more appropriate human capital accumulation would have been suitable. Second, the highly parametrized frictions of the labor market should be replaced by a search model. These two natural extensions are left for future research. 


\section{References}

\section{References}

Aiyagari, S. R. (1994). Uninsured idiosyncratic risk and aggregate saving. The Quarterly Journal of Economics, 109(3):659-84.

Bajari, P. and Kahn, M. E. (2005). Estimating housing demand with an application to explaining racial segregation in cities. Journal of Business \& Economic Statistics, 23:20-33.

Benabou, R. (1993). Workings of a city: Location, education, and production. The Quarterly Journal of Economics, 108(3):619-52.

Bewley, T. (1980). The optimum quantity of money. In J. Kareken and N. Wallace, eds., Models of Monetary Economies. Federal Reserve Bank of Minneapolis.

Blanden, J., Goodman, A., Gregg, P., and Machin, S. (2002). Changes in intergenerational mobility in britain. CEE Discussion Papers 0026, Centre for the Economics of Education, LSE.

Carroll, C. D. (1997). Why do the rich save so much? Economics Working Paper Archive 388, The Johns Hopkins University,Department of Economics.

Castaneda, A., Diaz-Gimenez, J., and Rios-Rull, J.-V. (2003). Accounting for the u.s. earnings and wealth inequality. Journal of Political Economy, 111(4):818-857.

Cutler, D. M. and Glaeser, E. L. (1997). Are ghettos good or bad? The Quarterly Journal of Economics, $112(3): 827-72$.

Davis, M. A. and Heathcote, J. (2005). Housing and the business cycle. International Economic Review, $46(3): 751-784$.

de Nardi, M. (2004). Wealth inequality and intergenerational links. Review of Economic Studies, 71:743768.

Dell, F., Piketty, T., and Saez, E. (2005). Income and wealth concentration in switzerland over the 20th century. CEPR Discussion Papers 5090, C.E.P.R. Discussion Papers.

Epple, D., Filimon, R., and Romer, T. (1993). Existence of voting and housing equilibrium in a system of communities with property taxes. Regional Science and Urban Economics, 23(5):585- 610.

Epple, D. and Platt, G. J. (1998). Equilibrium and local redistribution in an urban economy when households differ in both preferences and incomes. Journal of Urban Economics, 43(1):23 - 51. 
Epple, D. and Sieg, H. (1999). Estimating equilibrium models of local jurisdictions. The Journal of Political Economy, 107(4):645-681.

Fisher, J. D. M. (2007). Why does household investment lead business investment over the business cycle? Journal of Political Economy, 115:141-168.

Heer, B. (2001). Wealth distribution and optimal inheritance taxation in life-cycle economies with intergenerational transfers. Scandinavian Journal of Economics, 103(3):445-65.

Huggett, M. (1993). The risk-free rate in heterogeneous-agent incomplete-insurance economies. Journal of Economic Dynamics and Control, 17(5-6):953-969.

Huggett, M., Ventura, G., and Yaron, A. (2011). Sources of lifetime inequality. American Economic Review, 101(7):2923-54.

Iacoviello, M. and Pavan, M. (2009). Housing and debt over the life cycle and over the business cycle. Boston College Working Papers in Economics 723, Boston College Department of Economics.

Ioannides, Y. M. (2010). Neighborhood effects and housing. Discussion Papers Series, Department of Economics, Tufts University 0747, Department of Economics, Tufts University.

Keane, M. P. and Roemer, J. E. (2009). Assessing policies to equalize opportunity using an equilibrium model of educational and occupational choices. Journal of Public Economics, 93(8):879-898.

Keane, M. P. and Wolpin, K. I. (1997). The career decisions of young men. Journal of Political Economy, 105(3):473-522.

Kiyotaki, N. and Moore, J. (1997). Credit cycles. Journal of Political Economy, 105(2):211-48.

Kopczuk, W. and Saez, E. (2004). Top wealth shares in the united states: 1916-2000: Evidence from estate tax returns. NBER Working Papers 10399, National Bureau of Economic Research, Inc.

Krusell, P. and Smith, A. A. (1998). Income and wealth heterogeneity in the macroeconomy. Journal of Political Economy, 106(5):867-896.

Lee, D. (2005). An estimable dynamic general equilibrium model of work, schooling, and occupational choice. International Economic Review, 46(1):1-34.

Li, W., Liu, H., and Yao, R. (2009). Housing over time and over the life cycle: a structural estimation. Working Papers 09-7, Federal Reserve Bank of Philadelphia.

Li, W. and Yao, R. (2007). The life-cycle effects of house price changes. Journal of Money, Credit and Banking, 39(6):1375-1409. 
Lucas, R. J. and Prescott, E. C. (1974). Equilibrium search and unemployment. Journal of Economic Theory, 7(2):188-209.

Oreopoulos, P. (2003). The long-run consequences of living in a poor neighborhood. The Quarterly Journal of Economics, 118(4):1533-1575.

Piketty, T. (2000). Theories of persistent inequality and intergenerational mobility. In Atkinson, A. and Bourguignon, F., editors, Handbook of Income Distribution, volume 1 of Handbook of Income Distribution, chapter 8, pages 429-476. Elsevier.

Piketty, T. (2011). On the long-run evolution of inheritance: France 1820-2050. The Quarterly Journal of Economics, 126(3):1071-1131.

Piketty, T., Postel-Vinay, G., and Rosenthal, J.-L. (2006). Wealth concentration in a developing economy: Paris and france, 1807-1994. American Economic Review, 96(1):236-256.

Silos, P. (2007). Housing tenure and wealth distribution in life cycle economies. The B.E. Journal of Macroeconomics, $7(1): 27$.

Storesletten, K., Telmer, C. I., and Yaron, A. (2004). Consumption and risk sharing over the life cycle. Journal of Monetary Economics, 51(3):609-633.

Yang, F. (2009). Consumption over the life cycle: How different is housing? Review of Economic Dynamics, 12(3):423-443. 


\section{A Annexes}

\section{A.1 List of notations}

Table 9: List of notations

\begin{tabular}{|c|c|c|}
\hline Variables & Definition & Value/ grid \\
\hline \multicolumn{3}{|l|}{ Indexes } \\
\hline $\mathrm{i}$ & individual index & \\
\hline $\mathrm{n}$ & neighborhood index & \\
\hline \multicolumn{3}{|c|}{ Aggregate variables } \\
\hline $\mathrm{Y}$ & Production & 20 points \\
\hline $\mathrm{G}$ & Government expenditures & - \\
\hline $\mathrm{K}$ & Capital & 20 points \\
\hline$l$ & unit of labor productivity with $\sum l=L$ & 40 points \\
\hline \multicolumn{3}{|c|}{ State and choice variables } \\
\hline $\mathrm{a}$ & Age & $20-85$ \\
\hline $\mathrm{b}$ & bonds (wealth) & 700 points \\
\hline $\mathrm{c}$ & Consumption (goods) & 15 points \\
\hline d & Unemployment benefit & $0.8 * \underline{w}$ \\
\hline e & Labor market status & - \\
\hline h & Consumption (housing) & 15 points \\
\hline j & individual ability & $0-1$ \\
\hline$\iota$ & tenure & - \\
\hline $\mathrm{p}$ & housing price & - \\
\hline q & rent & - \\
\hline $\mathrm{r}$ & interest rate & 0.04 \\
\hline$\tilde{T}$ & Age of retirement & 65 \\
\hline $\mathrm{y}$ & Individual income & - \\
\hline $\mathrm{W}$ & human capital & $9-20$ \\
\hline $\mathrm{Z}$ & neighborhood level of social capital & $0-1$ \\
\hline \multicolumn{3}{|c|}{ Parameters } \\
\hline$\alpha$ & capital share & 0.32 \\
\hline$\beta$ & discount rate & 0.95 \\
\hline$\theta$ & deterministic probability to survive & see text \\
\hline$\Gamma$ & family size & see text \\
\hline$\psi$ & inherited or transmitted wealth & 0.25 \\
\hline$\varsigma$ & Parent's degree of altruism towards her child & 0.17 \\
\hline$\sigma$ & share of housing & 0.30 \\
\hline$\gamma$ & inverse of inter-temporal elasticity of substitution & 2 \\
\hline$\varpi$ & wage rate & \\
\hline$\chi$ & product per unit of labor productivity & \\
\hline$t_{y}$ & tax rate on income & 0.20 \\
\hline$t$ & tax rate on capital interest & 0.07 \\
\hline$t_{r}$ & tax rate on renters & 0.016 \\
\hline$t_{p r}$ & tax rate for real estate agencies & 0.003 \\
\hline$t_{p}$ & tax rate for homeowners & 0.005 \\
\hline$\delta_{h}$ & depreciation rate for housing & 0.015 \\
\hline$\delta_{k}$ & depreciation rate for capital & 0.01 \\
\hline$\tau_{h}$ & transaction cost & 0.15 \\
\hline$\lambda$ & Job arrival rate & see text \\
\hline$\vartheta$ & Job destruction rate & 0.04 \\
\hline$\kappa$ & downpayment rate & 0.3 \\
\hline$\Pi$ & distribution over population, $\Pi_{a}, \Pi_{Z}, \Pi_{W}, \Pi_{J}, \Pi_{b n}$ & \\
\hline
\end{tabular}




\section{A.2 Computation details}

\section{A.2.1 Updating procedure of housing prices}

Initial prices : Let's assume that the prices are constant:

$$
p_{1}^{n}=p_{2}^{n}=p_{3}^{n}=\ldots=\ldots=p_{t}^{n}==p_{t+1}^{n}==p_{T-1}^{n}==p_{T}^{n} \quad \text { or put differently } \quad \frac{p_{T-1}^{n}}{p_{T}^{n}}=1
$$

Under constant price assumption, using former simulations, I can derive housing demand $H_{t}^{D}=$ $H_{t}^{H^{D}}+H_{t}^{R^{D}} \mathrm{t}$ for each period in each neighborhood. However, the prices determination require only housing demand for homeowners. Housing supply is exogenous in our model and given by $H_{t}^{S}=H_{t}^{H^{S}}+$ $H_{t}^{R^{S}}$. The equilibrium price at $\mathrm{t}=1, p_{1}^{n(1)}$, is determined by market clearing condition $H_{t}^{H^{S}}=H_{t}^{R^{S}}$

Update and convergence I assume that for the sequences $\mathrm{k}-1$ and $\mathrm{k}$ of equilibrium prices, the ratio between period is constant: $\quad \frac{p_{t+1}^{n(k)}}{p_{t}^{n(k)}}=\frac{p_{t+1}^{n(k-1)}}{p_{t}^{n(k-1)}} \quad \forall k$

The equilibrium prices are derived assuming that the ratio between current and next prices are the same as in the first sequence $\left\{p_{t}^{n(1)}\right\}_{t=1}^{T}$. Since the prices of the first sequence are recovered from the constant price assumption, I can expect their ratio to speed-up the convergence. At time $t=1$, I derive housing demand under the constant price ratio assumption, and derive $\left\{p_{t}^{n(2)}\right\}_{t=1}^{T}$. Using the same strategy, I can recover the entire sequence $\left\{p_{t}^{n(2)}\right\}_{t=1}^{T}$.

Finally, I keep updating using the former price ratio until $\left|\left\{p_{t}^{n(k)}\right\}_{t=1}^{T}-\left\{p_{t}^{n(1)}\right\}_{t=1}^{T}\right|$ where $\epsilon$ is a defined criterion. The corresponding prices are the rational expectation equilibrium prices and given by $\left\{p_{t}^{n}\right\}_{t=1}^{T}$

\section{A.2.2 Discretization and Parametrization}

Family size and consumption In order to adjust the housing and consumption profile for a typical household I use a household equivalence scale. The aim is to keep the welfare of the family constant as the family size varies over the life-cycle.

Table 10: Family size and consumption

\begin{tabular}{lcc}
\hline $\begin{array}{l}\text { Family } \\
\text { size }\end{array}$ & $\begin{array}{c}\text { Housing } \\
\text { consumption }\end{array}$ & $\begin{array}{c}\text { Goods } \\
\text { consumption }\end{array}$ \\
\hline 1 & 100 & 100 \\
2 & 120 & 130 \\
3 & 150 & 160 \\
4 & 180 & 205 \\
5 & 210 & 250 \\
\hline Equivalence scale between housing and non housing consumption
\end{tabular}


Education: I assume that the education level acquired by an individual is a function of its birth neighborhood and its ability. The levels of education goes from 9 to 20. I bound the minimum level of education to reflect the fact that education is compulsory until age 16. Half of education is due to ability, and half to the birth neighborhood. It may be argued that locations do not reflect half of educational differences across individuals. The location served two purposes: it reflects the human capital acquisition cost, and

Life and death: The probability to survive are derived from the INED tables of life expectancy. ${ }^{15}$. I scaled the expectancy tables such that at age 80 the survival rate is equal to 0 . The corresponding survival probability is given by Figure 12 .

Figure 12: Survival over the life cycle

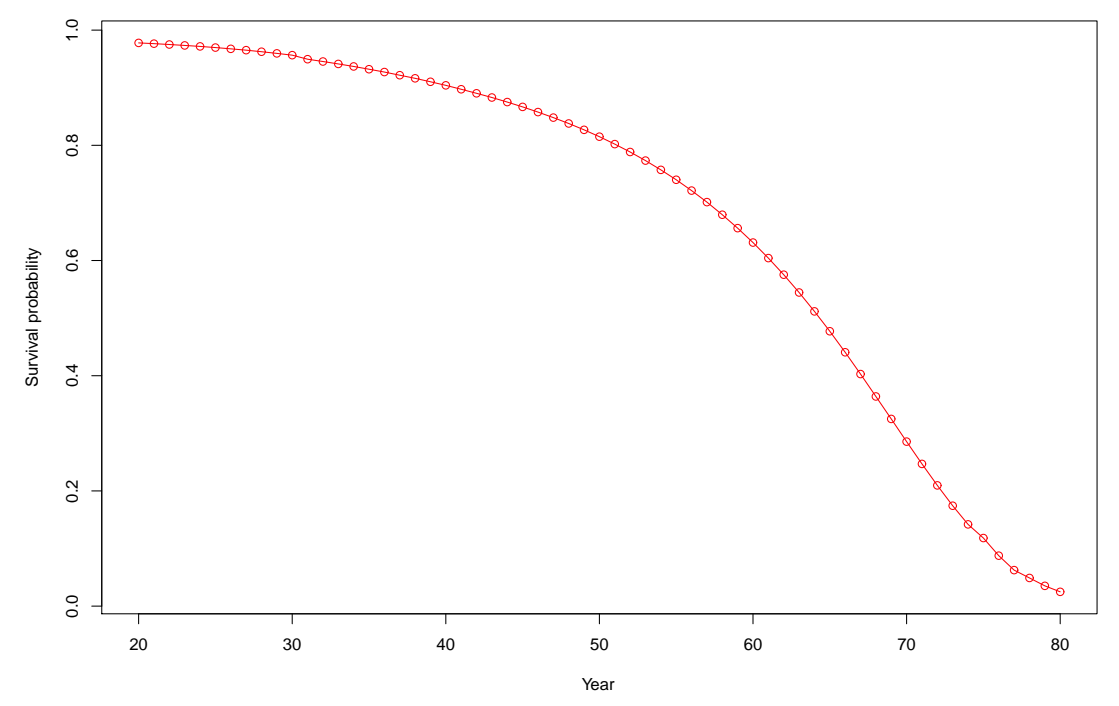

The level of social capital: I define the level of social capital $z$ to be a function of three variables evaluated at the neighborhood level: mean education level, unemployment rate and the homeownership rate. The precise specification is the following.

$$
z_{n}=a_{1} \cdot e d u_{n}+a_{2} \cdot \text { unemp }_{n}+a_{3} \cdot \text { home }_{n}
$$

In this specification, I put a higher weight on education. I specify $a_{1}, a_{2}$ and $a_{3}$ such that respectively $55 \%, 30 \%$ and $15 \%$ of the level of social capital are explained by education, unemployment and homeownership rate.

\footnotetext{
${ }^{15}$ Institut National des Etudes demographiques is the French office for demographic studies
} 
The productivity process: The productivity function is given by:

$$
l_{a} j z w=\sum_{a} b_{1} * l_{a}+b_{2} * l_{j}+b_{3} * l_{z}+b 4 * l_{w}
$$

In order to get the parameters $b$, I estimate this equation on the labor surveys and replacing individual unobserved by a fixed effect. After extensive analysis, I choose the parameters $b$ such that $40 \%$ of the wage is explained by education. The three others variables (age, location, ability) account each for $20 \%$ of the productivity.

I assume the following structure between age and productivity.

$$
\begin{aligned}
& l_{a}=\sqrt{a} \quad \text { if } \quad 20<a<30 \\
& l_{a}=l_{a-1}+\log (a+1)-\log (a) \quad \text { if } \quad 31<a<45 \\
& l_{a}=l_{a-1}+\sqrt{(a+1)-\sqrt{(} a)} \text { if } \quad 46<a<66
\end{aligned}
$$

Figure 13: Wage over the life cycle

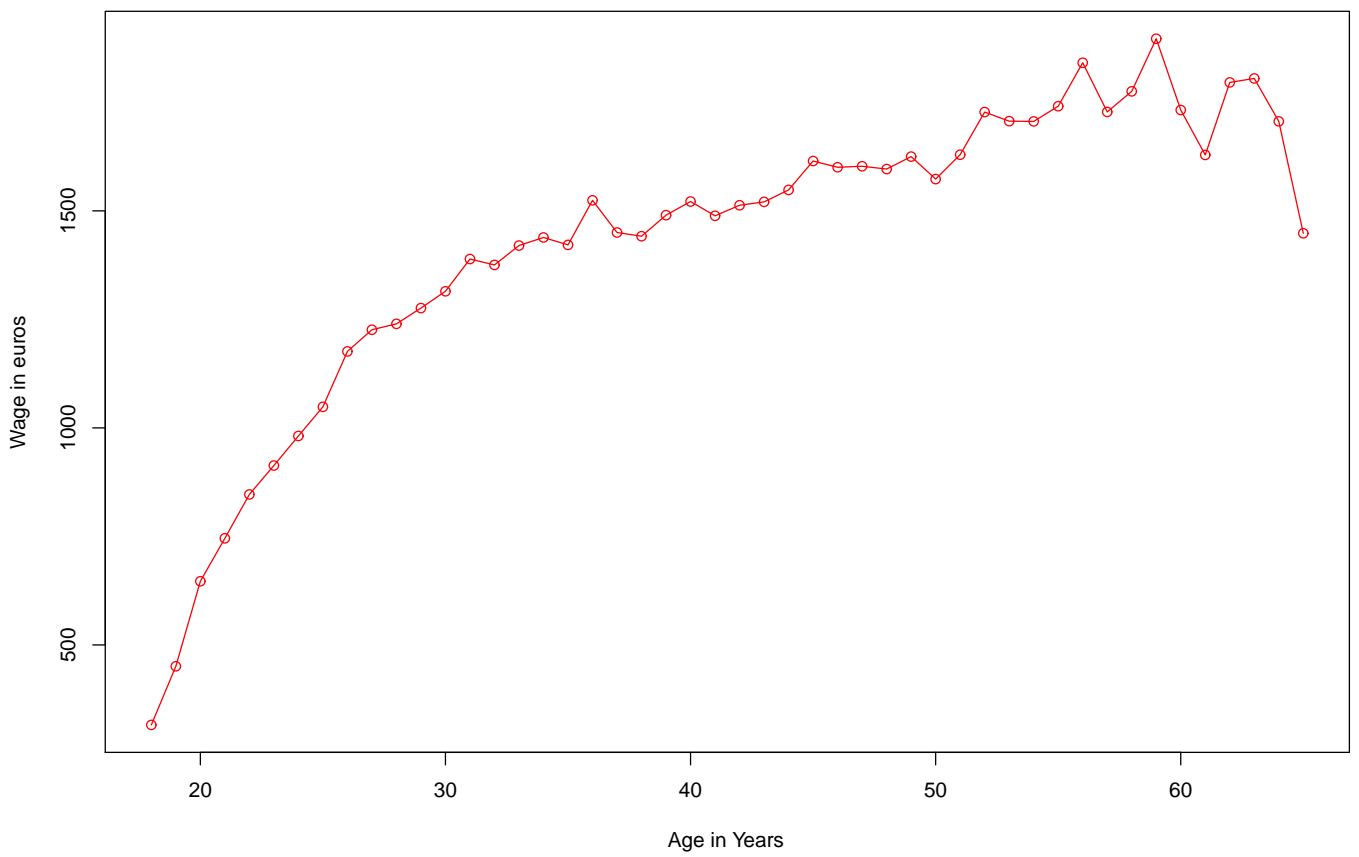

Labor market: I assume that labor market is equilibrium. That is, the flow of workers finding a job is similar to the flow of workers laid-off. I need to assume how individuals leave unemployment. To do so, I estimate using the 2002 Labor Survey, a duration model of unemployment. I estimate a hazard function out of unemployment. This yields a negative time-dependency. Moreover, for each neighborhood 
a hazard rate out of unemployment is estimated.

Once the initial job arrival is set-up, its evolution follows a first-order markov process. The level of autocorrelation over time is assumed to be proportional to changes in the level of social capital.

Initial school differences: The distribution of $i^{f}$ is simulated to fit the differences between locations in high school graduation rates.

Matching the model and the data at the initial period: To produce a good fit, several calibrations are imposed by the model. First, the wage rate is used to match the wage profile over the life-cycle. In addition, the interest rate along with assumptions on the productivity process help fitting the unemployment rate over the life-cycle. Spatial differences in unemployment is captured by a calibrated neighborhood-specific job arrival. Spatial differences in the wage profile are captured through the initial distribution of education and social capital across locations.

It is not trivial to match the moments of the housing market. However, the depreciation rate of housing, the initial distribution of prices, the residential and property taxes are very useful tools in matching both the mean homeownership rate and its distribution over locations. Our calibrated parameters are obtained after a fine tuning allowing to match the data and the model at the initial period.

Finally, it is not trivial to match the wealth distribution. Nonetheless, it turns out that the work achieved on the housing market helps fitting the shape and the left-tail of the wealth distribution. In the dynamic setup, the evolution of prices succeeds in matching the top percentiles. The local differences in the outcome of the housing market generates a local wealth distribution that fits extremely well the data. 